Supporting Information

\title{
Iterative Radical Addition with a Special Monomer Carrying Bulky and Convertible Pendant: A New Concept toward Controlling the Sequence for Vinyl Polymers
}

Dongyoung $\mathrm{Oh}^{1}$, Makoto Ouchi* ${ }^{1,2}$, Tomoya Nakanishi ${ }^{1}$, Hirotomo Ono ${ }^{1}$, and Mitsuo Sawamoto*1

${ }^{1}$ Department of Polymer Chemistry, Graduate School of Engineering, Kyoto University, Katsura, Nishikyo-ku, Kyoto 615-8510, Japan

${ }^{2}$ Precursory Research for Embryonic Science and Technology (PRESTO), Japan Science and Technology Agency (JST), 4-1-8 Kawaguchi, Saitama 332-0012, Japan 


\section{Experimental Section}

\section{Materials}

The following reagents were used as received: $\alpha$-chlorophenylacetyl chloride (Aldrich, $>90 \%$ ), 1-dodecanol (TCI, >99.0\%), 2-isopropyl-2-adamantyl methacrylate (IPAMA; TCI, >98.0\%), trifluoroacetic acid (TFA: Wako, >98.0\%), methanol (Wako, >99.8\%), ethanol (Wako, >99.5\%), 3-phenyl-1-propanol (TCI, >98.0\%), propargyl alcohol (Aldrich, >99.0\%), 3-buten-1-ol (TCI, $>98.0 \%), \quad \mathrm{N}-(3-D i m e t h y l a m i n o p r o p y l)-\mathrm{N}$ '-ethylcarbodiimide hydrochloride (EDC-HCl: TCI, $>98.0 \%$ ), $N, N$ '-diisopropylcarboiimide (DIC;: TCI, >97.0\%), 4-dimethylaminopyridine (DMAP: TCI, $>99.0 \%$ ). Triethylamine (TCI, $>99.0 \%$ ) was dried overnight over calcium chloride and distilled before use. Column chromatography was carried out using Wakosil C300 (Wako) as the stationary phase.

All reagents for ruthenium catalyst, listed below, were used as received without further purification and handled in a glovebox (MBraun Labmaster 130, M. Braun Inter-gas-systeme GmbH, Garching, Germany) under a moisture- and oxygen-free argon atmosphere $\left(\mathrm{H}_{2} \mathrm{O}<0.1 \mathrm{ppm} ; \mathrm{O}_{2}<0.1\right.$ ppm): Ruthenium(III) Chloride hydrate (Wako, > 99.9\%), 1,2,3,4,5-pentamethylcyclopentadiene (TCI, > 93\%), lithium triethylhydridoborate (Aldrich, $1.0 \mathrm{M}$ solution in THF), 1,2-bis(diphenylphosphino)-ethane monoxide (BPMO Ligand: Aldrich, > 97\%). The ruthenium precursor $\left[\mathrm{Cp} * \mathrm{Ru}\left(\mu_{3}-\mathrm{Cl}\right)\right]_{4}$ was synthesized as described in the literature. ${ }^{1}$

Toluene (Kishida kagaku, Osaka, Japan; purity 99.5\%) was dried and purified by passing through purification columns (Solvent Dispensing System, SG Water USA, Nashua, NH; Glass Contour) and bubbled with dry nitrogen for more than $30 \mathrm{~min}$ immediately before use. 1,2,3,4-tetrahydrousnaphthalene (tetralin; internal standard for ${ }^{1} \mathrm{H}$ NMR) were dried over calcium chloride and distilled from calcium hydride. Unless stated otherwise, all the solvents were purchased from Wako Pure Chemical Industries and used without further purification.

\section{Measurements}

The product for each step was purified by preparative recycling SEC (column: Jasco KF-5001) connected to a Jasco PU-2086 precision pump, a Jasco RI-2031 refractive-index detector and a Jasco UV-2075 ultraviolet detector. ${ }^{1} \mathrm{H}$ NMR spectra were recorded on a JEOL JNM-ECA500 spectrometer, operating at 500.125 MHZ. Electrospray-ionization mass spectra (ESI-MS) were measured on a Waters Quattro micro API. 


\section{Hydrolysis of IPAMA}

IPAMA (0.105 g, $0.40 \mathrm{mmol})$ were placed in glass tube and dissolved in dichloromethane (DCM, $10 \mathrm{~mL})$. To this resultant solution, TFA $(0.15 \mathrm{~mL}, 2.0 \mathrm{mmol})$ were added at $0{ }^{\circ} \mathrm{C}$ while stirring for $30 \mathrm{~min}$. After the reaction mixture was concentrated under reduced pressure at $40{ }^{\circ} \mathrm{C}$, and subsequently measured with ${ }^{1} \mathrm{H}$ NMR (Figure S1-A).

\section{Selective Acidolysis of IPAMA}

IPAMA $(0.105 \mathrm{~g}, 0.40 \mathrm{mmol})$ and MMA $(0.043 \mathrm{~mL}, 0.40 \mathrm{mmol})$ were placed in glass tube and dissolved in DCM $(10 \mathrm{~mL})$. To this resultant solution, TFA $(0.15 \mathrm{~mL}, 2.0 \mathrm{mmol})$ were added at $0{ }^{\circ} \mathrm{C}$ while stirring for $30 \mathrm{~min}$. Subsequently, the reaction mixture was measured with ${ }^{1} \mathrm{H}$ NMR (Figure S1-B).

\section{Synthesis of dodecyl 2-choloro-2-phenylacetate (DCPA: Initiator)}

Triethylamine $(25.4 \mathrm{~mL}, 183 \mathrm{mmol})$ and 1-dodecanol $(34.1 \mathrm{~mL}, 152 \mathrm{mmol})$ were placed in round-bottom flask under argon and then dissolved in DCM $(500 \mathrm{~mL})$. To the resultant solution, $\alpha$-chlorophenylacetyl chloride $(26.3 \mathrm{~mL}, 166 \mathrm{mmol})$ was gradually added at $0{ }^{\circ} \mathrm{C}$, while stirring for $30 \mathrm{~min}$. The reaction solution was warmed to room temperature and stirred overnight. To the solution, $600 \mathrm{~mL}$ of $\mathrm{Et}_{2} \mathrm{O}$ were added, followed by addition of $600 \mathrm{~mL}$ of sat. $\mathrm{NaHCO}_{3}$ solution. The organic layer was washed with brine 3 times and dried on $\mathrm{Na}_{2} \mathrm{SO}_{4}$. After concentration under reduced pressure, the crude product was purified with silica column chromatography (hexane:ethyl acatate $=95: 5)$. The product was obtained as slightly yellow oil $(153 \mathrm{mmol}, 92 \%)$. The ${ }^{1} \mathrm{H}$ NMR spectrum was shown in Figure S2: ${ }^{1} \mathrm{H}$ NMR (in $\mathrm{CDCl}_{3}$ ): 7.49 (dd, 2H), 7.41-7.33 (m, 3H), 5.34 (s, 1H), $4.15(\mathrm{t}, 2 \mathrm{H}), 1.60$ (quint, 2H), 1.34-1.17 (m, 18H), $0.88(\mathrm{t}, 3 \mathrm{H})$. The ESI-MS spectrum was shown in Figure S3: observed; $361.20 \mathrm{~m} / \mathrm{z}$, calculated (+ Na); $361.19 \mathrm{~m} / \mathrm{z}$. 


\section{Ruthenium-catalyzed radical addition of IPAMA with DCPA in 1st cycle}

The typical procedure is given as below: $\left[\mathrm{Cp} * \mathrm{Ru}\left(\mu_{3}-\mathrm{Cl}\right)\right]_{4}(0.31 \mathrm{~g}, 0.29 \mathrm{mmol})$ and BPMO ligand $(0.96 \mathrm{~g}, 2.3 \mathrm{mmol})$ were placed in round-bottom flask under argon and dissolved in toluene $(280 \mathrm{~mL})$. The solution was heated to $80{ }^{\circ} \mathrm{C}$ for $1 \mathrm{~h}$ to prepare ruthenium complex: here, the color changed from black-red to yellow-brown. Separately, IPAMA (15.2 g, $57.9 \mathrm{mmol})$ was placed in another round-bottom flask under argon. After cooling the ruthenium complex solution to room temperature, the solution was transferred to IPAMA. To the resultant solution, tetralin $(1.40 \mathrm{~mL})$ and DCPA (initiator, $2.0 \mathrm{~mL}, 5.80 \mathrm{mmol}$ ) was added and subsequently stirred for $4 \mathrm{~h}$ at $100{ }^{\circ} \mathrm{C}$. After the reaction mixture was concentrated under reduced pressure at $40{ }^{\circ} \mathrm{C}$, the crude product was passed through a neutral silica column chromatography (hexane:ethyl acatate $=1: 4$ ) to remove $\mathrm{Ru}$ catalyst, followed by purification with preparative recycling SEC technique. The product (I) was obtained as slightly yellow oil (4.93 mmol, $85 \%)$. The ${ }^{1} \mathrm{H}$ NMR spectrum was shown in Figure S4: ${ }^{1} \mathrm{H}$ NMR (Figure S4, in $\left.\mathrm{CDCl}_{3}\right)$ : 7.34-7.21 (m, 5H), 4.12-3.96 (m, 2H), 3.94-3.76 (m, 1H), 3.18-3.02 (m, 1H), 2.73-2.40 (m, 4H), 2.00-1.58 (m, 15H), 1.54 (quintet, $2 \mathrm{H}), 1.34-1.17(\mathrm{~m}, 18 \mathrm{H})$, 1.02-0.97 (dt, 6H), $0.88(\mathrm{t}, 3 \mathrm{H})$. The ESI-MS spectrum was shown in Figure S5: observed; 623.40 $\mathrm{m} / \mathrm{z}$, calculated (+ Na); $623.40 \mathrm{~m} / \mathrm{z}$.

\section{Selective acidolysis of the single unit adduct of IPAMA in 1st cycle}

The typical procedure of cleavage is given as below: the IPAMA adduct (I, $0.73 \mathrm{~g}, 1.22 \mathrm{mmol})$ were placed in glass tube under argon and dissolved in DCM $(30 \mathrm{~mL})$. To this resultant solution, TFA $(0.47 \mathrm{~mL}, 6.14 \mathrm{mmol})$ was added at $0{ }^{\circ} \mathrm{C}$ while stirring for $30 \mathrm{~min}$. After the reaction mixture was concentrated under reduced pressure at $40{ }^{\circ} \mathrm{C}$, the crude product was purified with preparative recycling SEC technique. The methacrylic acid product II was obtained as slightly yellow oil (1.13 mmol, $93 \%$ ). The ${ }^{1} \mathrm{H}$ NMR spectrum was shown in Figure S6: ${ }^{1} \mathrm{H}$ NMR (Figure S6, in $\mathrm{CDCl}_{3}$ ): 7.34-7.21 (m, 5H), 4.09-3.99 (m, 2H), 3.94-3.85 (m, 1H), 3.13-2.92 (m, 1H), 2.58-2.37 (m, 1H), 1.79-1.72 (d, 3H), $1.54(\mathrm{sext}, 2 \mathrm{H})$ 1.34-1.14 (m, 18H), $0.88(\mathrm{t}, 3 \mathrm{H})$. The ESI-MS spectrum was shown in Figure S7: observed; $447.21 \mathrm{~m} / \mathrm{z}$, calculated $(+\mathrm{Na}) ; 447.23 \mathrm{~m} / \mathrm{z}$.

\section{Esterification with methanol in 1 st cycle}

The typical procedure of cleavage is given as below: the methacrylic acid adduct (II, $0.785 \mathrm{~g}$, $1.85 \mathrm{mmol})$ and DMAP $(22.6 \mathrm{mg}, 0.19 \mathrm{mmol})$ were placed in round-bottom flask under argon and dissolved in DCM $(60 \mathrm{~mL})$. To this resultant solution, DIC $(0.43 \mathrm{~mL}, 2.77 \mathrm{mmol})$ and methanol $(0.75 \mathrm{~mL}, 18.5 \mathrm{mmol})$ were added at $0{ }^{\circ} \mathrm{C}$ and subsequently stirred for $1 \mathrm{~h}$. The solution was 
warmed to room temperature and stirred for $24 \mathrm{~h}$. After the reaction mixture was concentrated under reduced pressure at $40{ }^{\circ} \mathrm{C}$, the crude product was purified with preparative recycling SEC technique to remove DIC and DMAP, followed by purification with a neutral silica column chromatography (eluent: ethyl acatate) to remove by-product (activated ester or carboxylic anhydride). The methanol-esterified product was obtained as slightly yellow oil (1.23 mmol, $69 \%)$. The ${ }^{1} \mathrm{H}$ NMR spectrum was shown in Figure S8: ${ }^{1} \mathrm{H}$ NMR (Figure S8, in $\mathrm{CDCl}_{3}$ ): 7.34-7.21 $(\mathrm{m}, 5 \mathrm{H}$ ), 4.08-3.98 (m, 2H), 3.92-3.84 (m, 1H), 3.68-3.4 (d, 3H), 3.09-2.86 (m, 1H), 2.58-2.34 (m, 1H), 1.73 $(\mathrm{d}, 3 \mathrm{H}), 1.53$ (quintet, $2 \mathrm{H}), 1.34-1.14(\mathrm{~m}, 18 \mathrm{H}), 0.88(\mathrm{t}, 3 \mathrm{H})$. The ESI-MS spectrum was shown in Figure S9: observed; $461.21 \mathrm{~m} / \mathrm{z}$, calculated (+ Na); $461.24 \mathrm{~m} / \mathrm{z}$.

Procedures for 3 steps (radical addition, acidolysis, and esterification) in 2 nd and 3 rd cycles were also done similar to those in 1st cycle. ${ }^{1} \mathrm{H}$ NMR and ESI-MS spectrum of products are shown below. 


\section{A. Acidolysis of IPAMA}

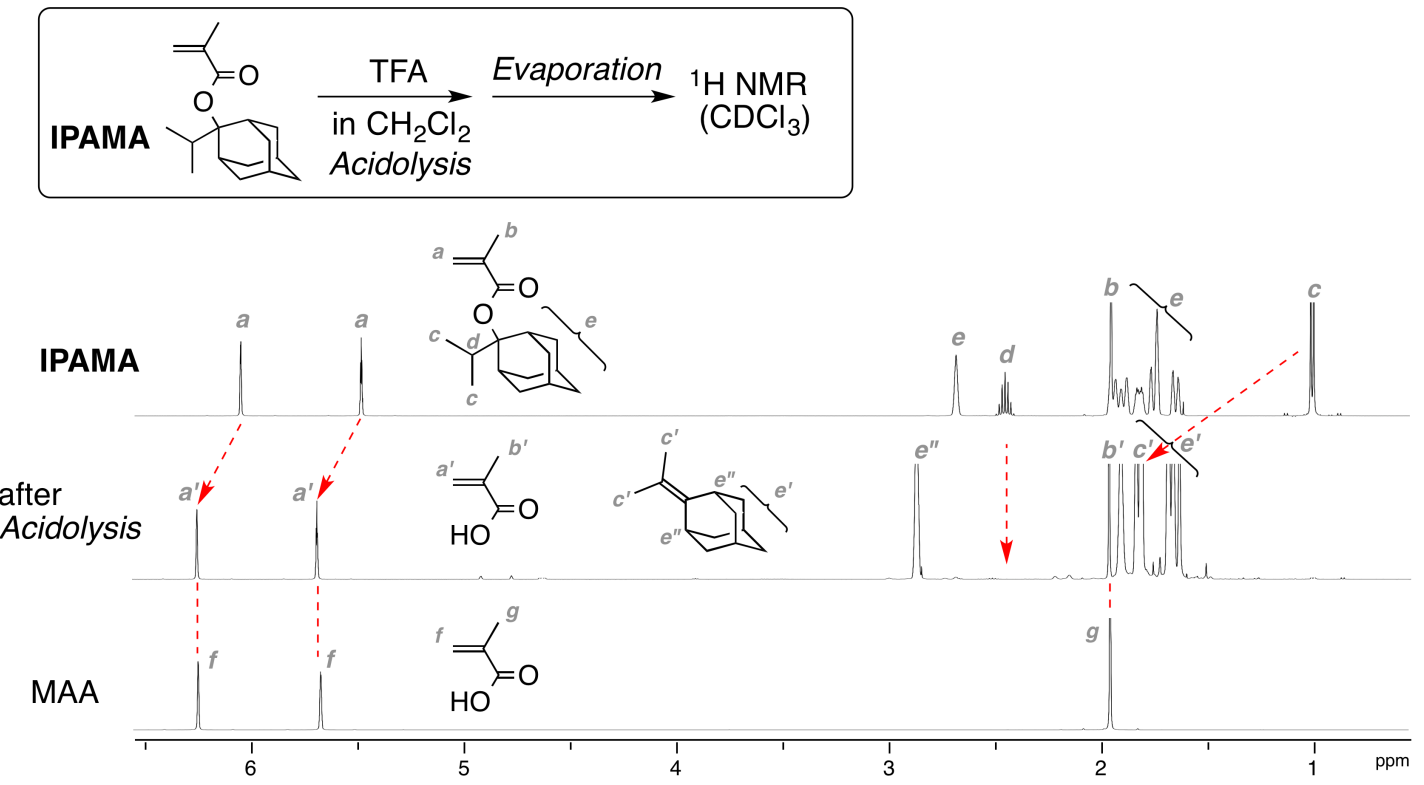

B. Selective Acidolysis of IPAMA

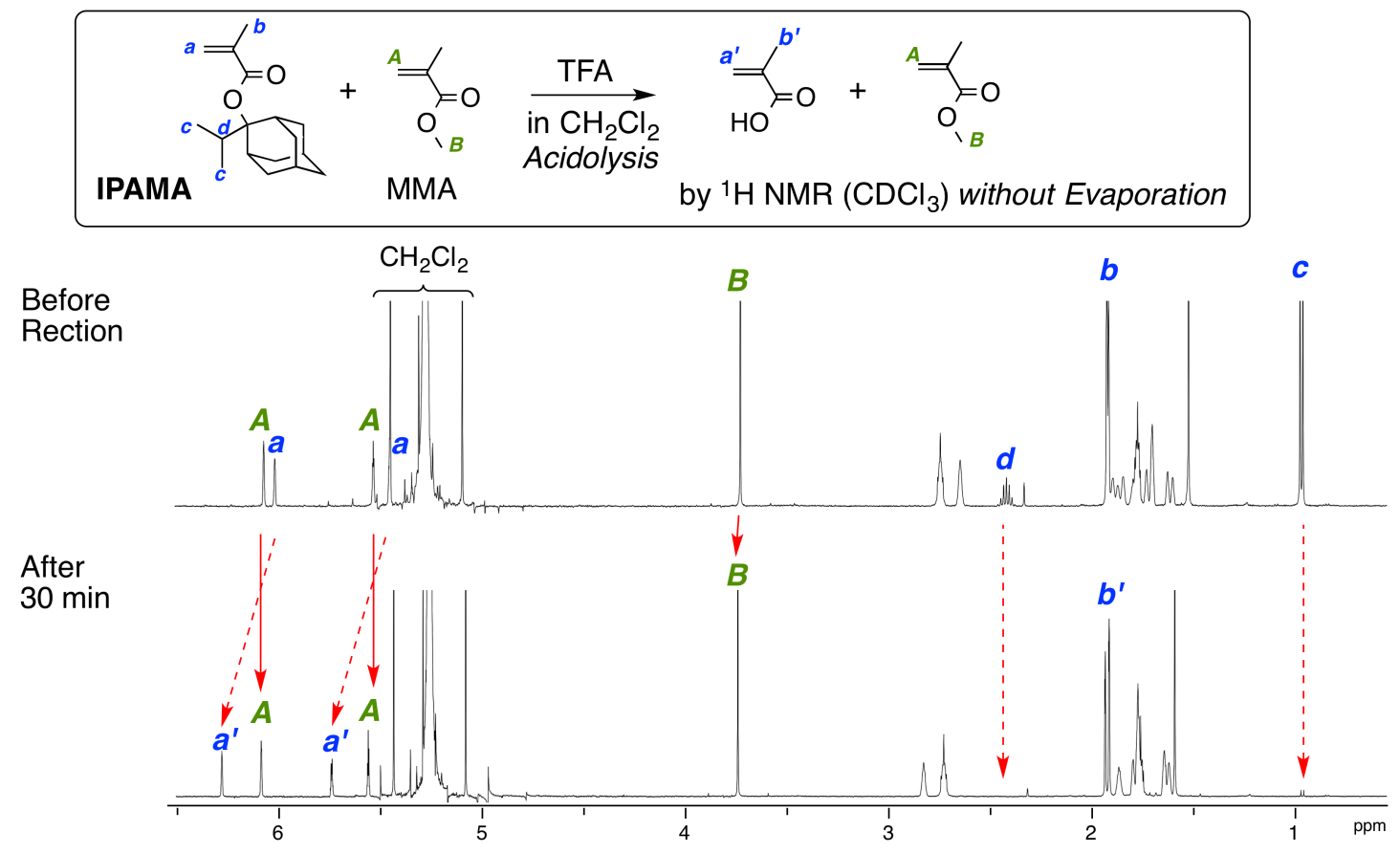

Figure S1. (A) ${ }^{1}$ H NMR Spectra of IPAMA before and after Acidolysis. (B) ${ }^{1}$ H NMR Spectra of Selective Acidolysis Model Reaction 


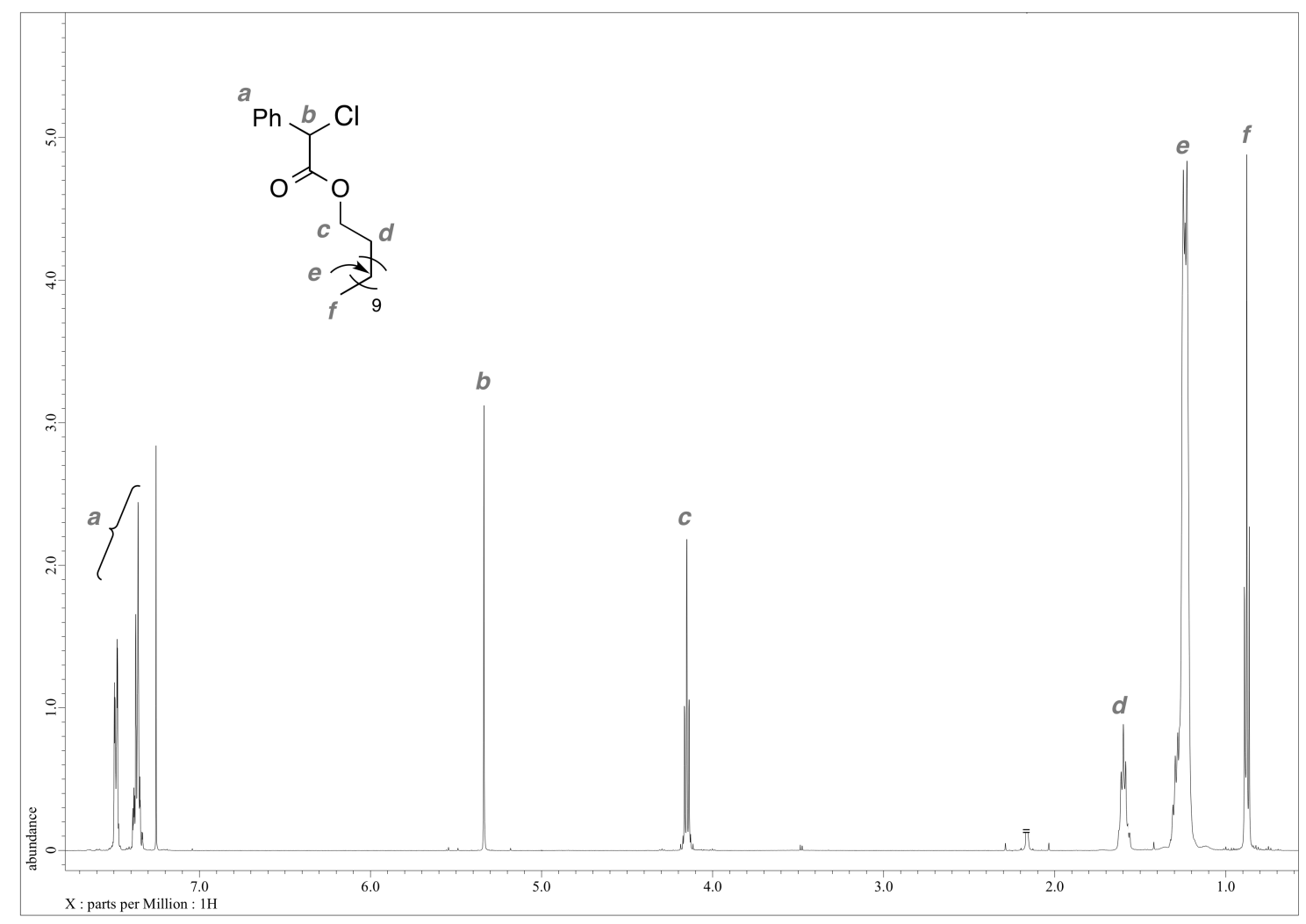

Figure S2. ${ }^{1}$ H NMR Spectrum of Initiator

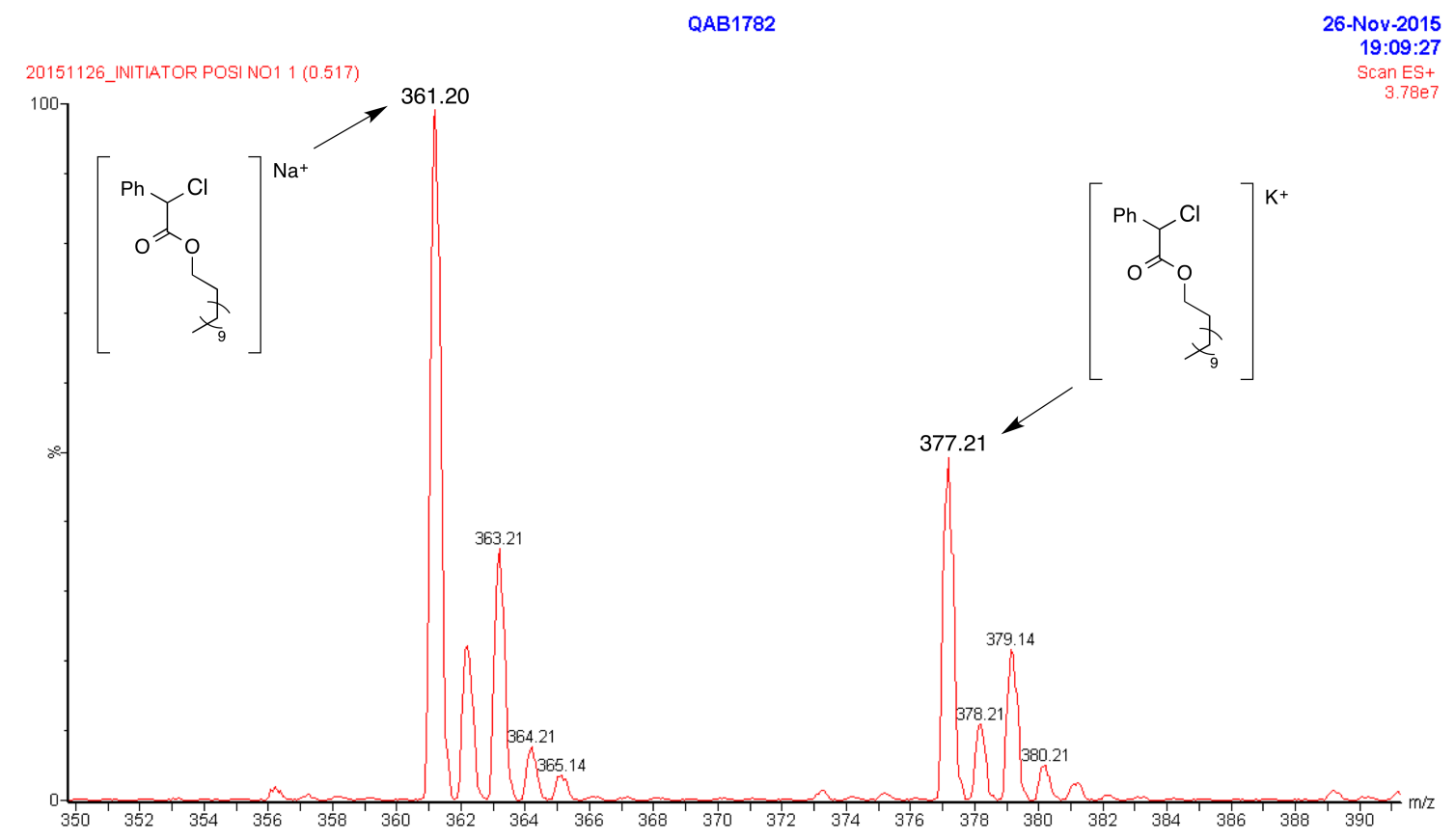

Figure S3. ESI-MS Spectrum of Initiator 


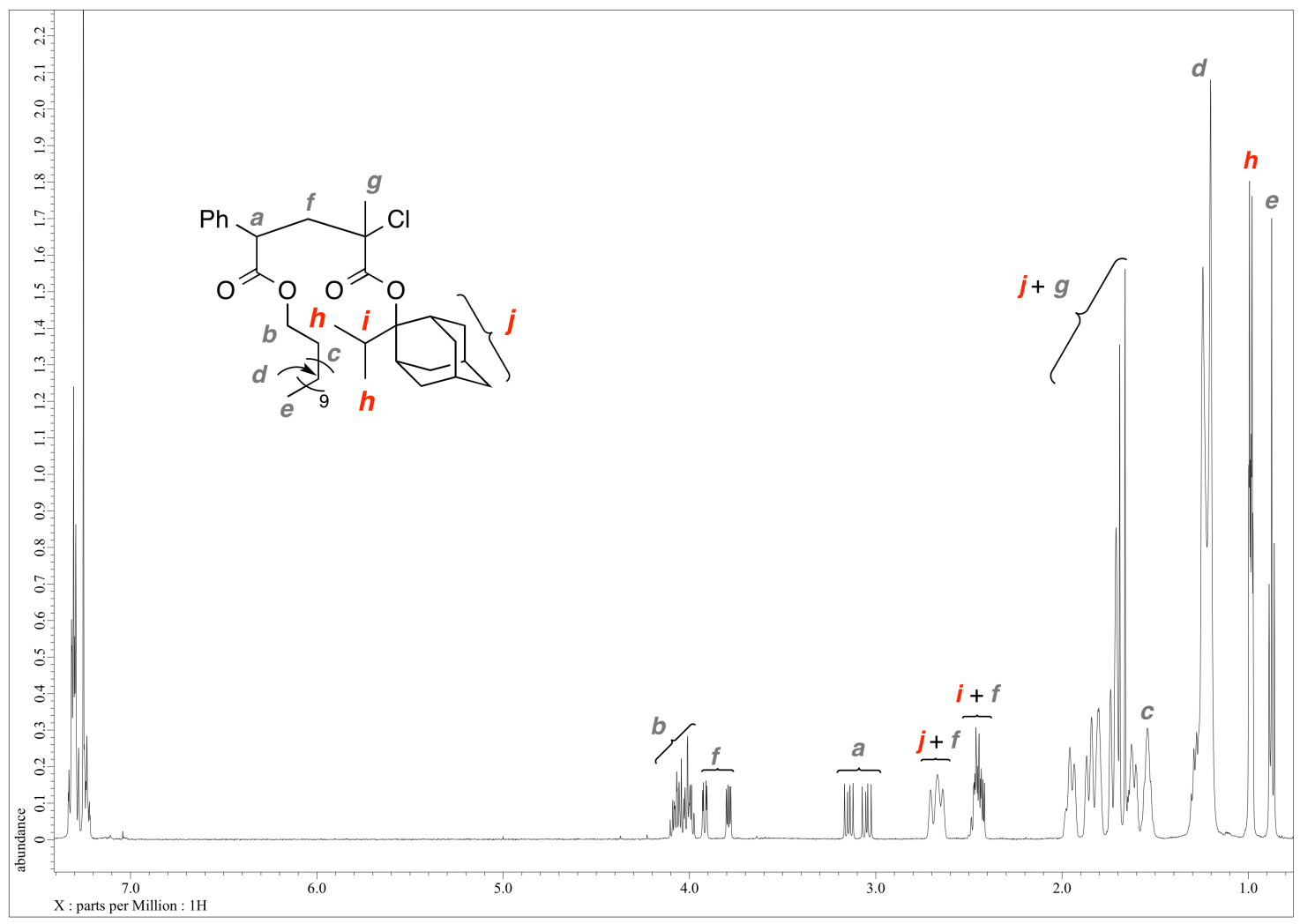

Figure S4. ${ }^{1} \mathrm{H}$ NMR Spectrum of Single-Adduct $\left({ }^{\text {st }}\right.$ Cycle $)$

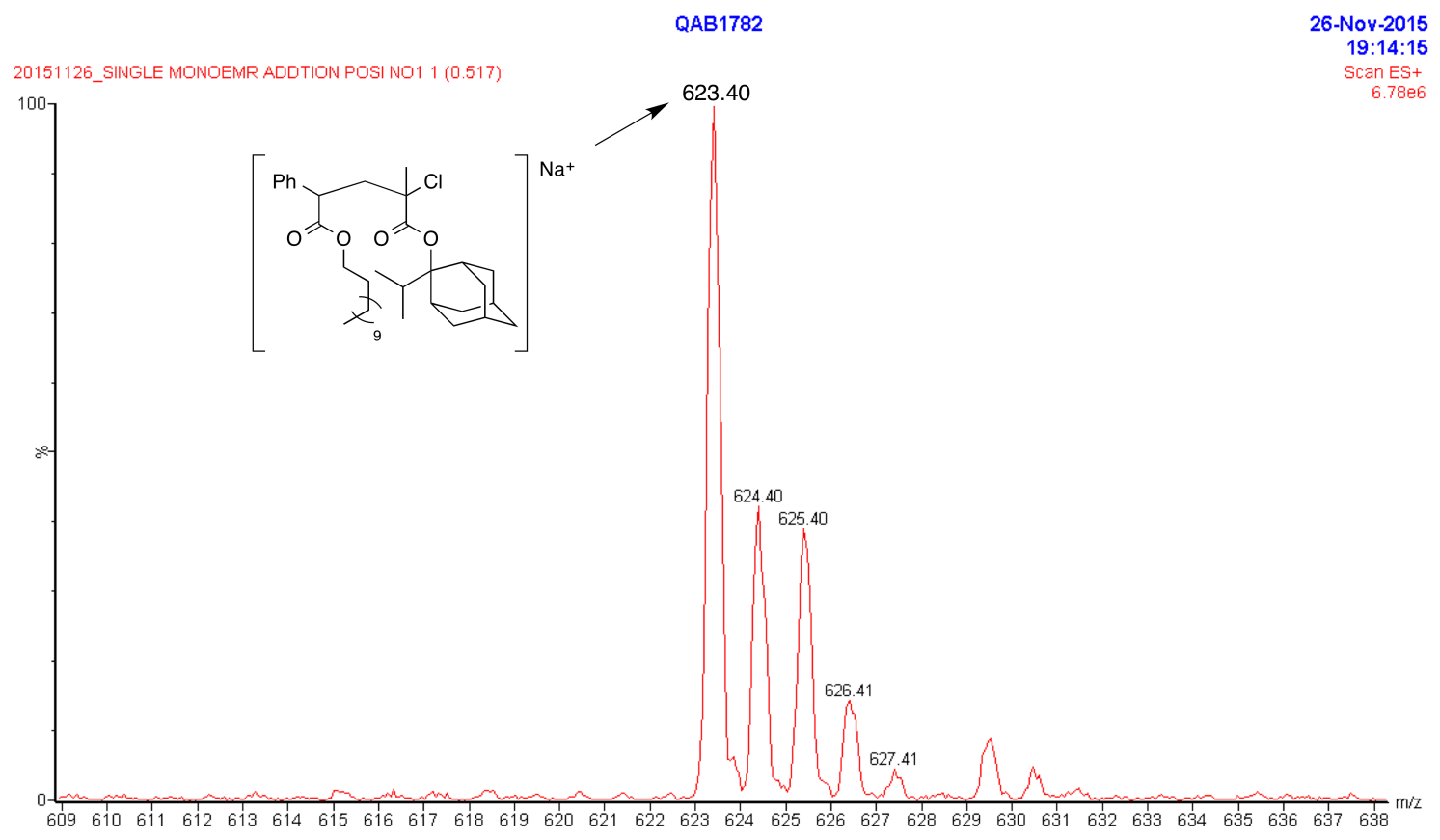

Figure S5. ESI-MS Spectrum of Single-Adduct $\left(1^{\text {st }}\right.$ Cycle $)$ 


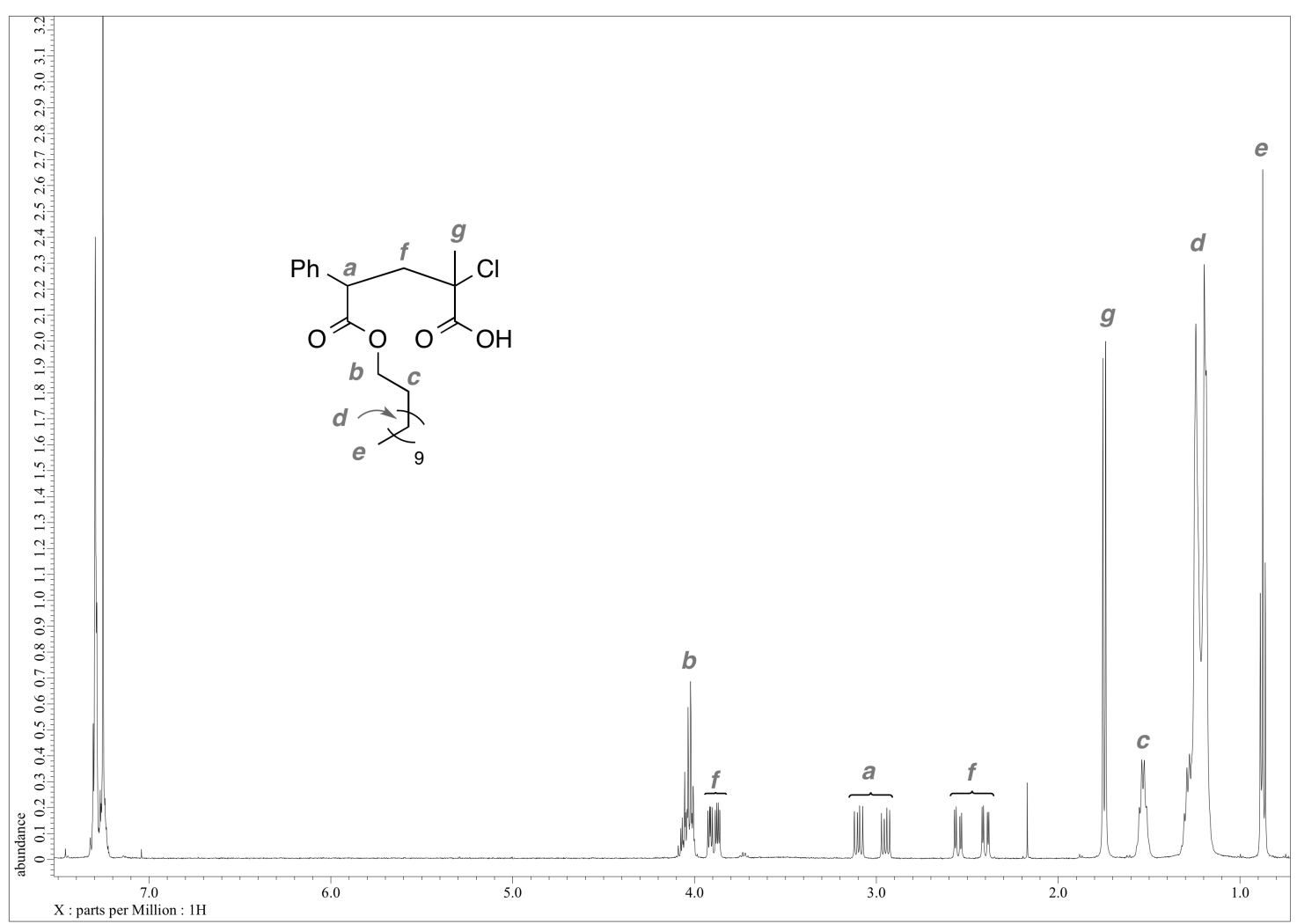

Figure S6. ${ }^{1}$ H NMR Spectrum of Product after Selective Cleavage $\left(1^{\text {st }}\right.$ Cycle $)$

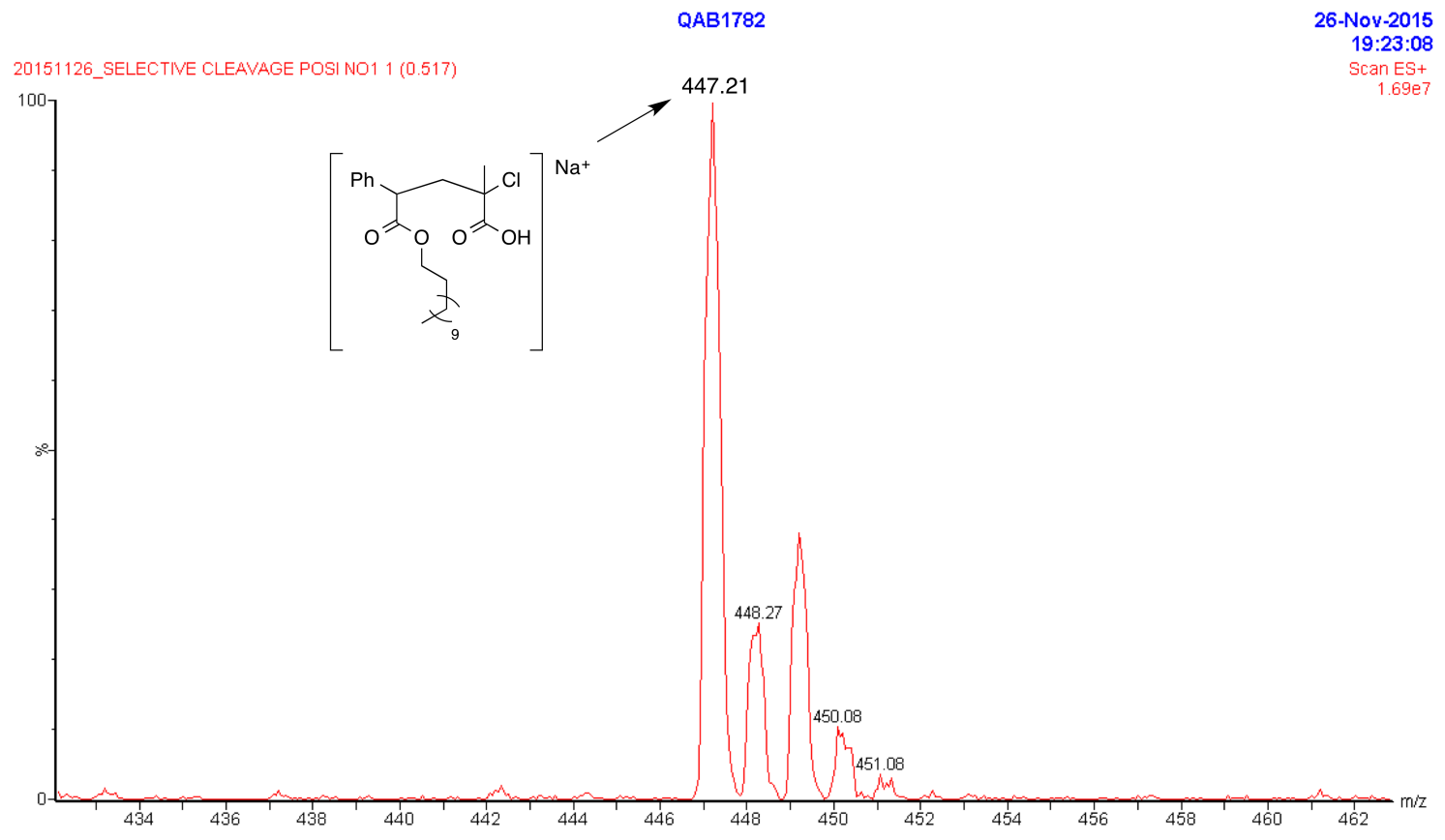

Figure S7. ESI-MS Spectrum of Product after Selective Cleavage $\left(1^{\text {st }}\right.$ Cycle) 


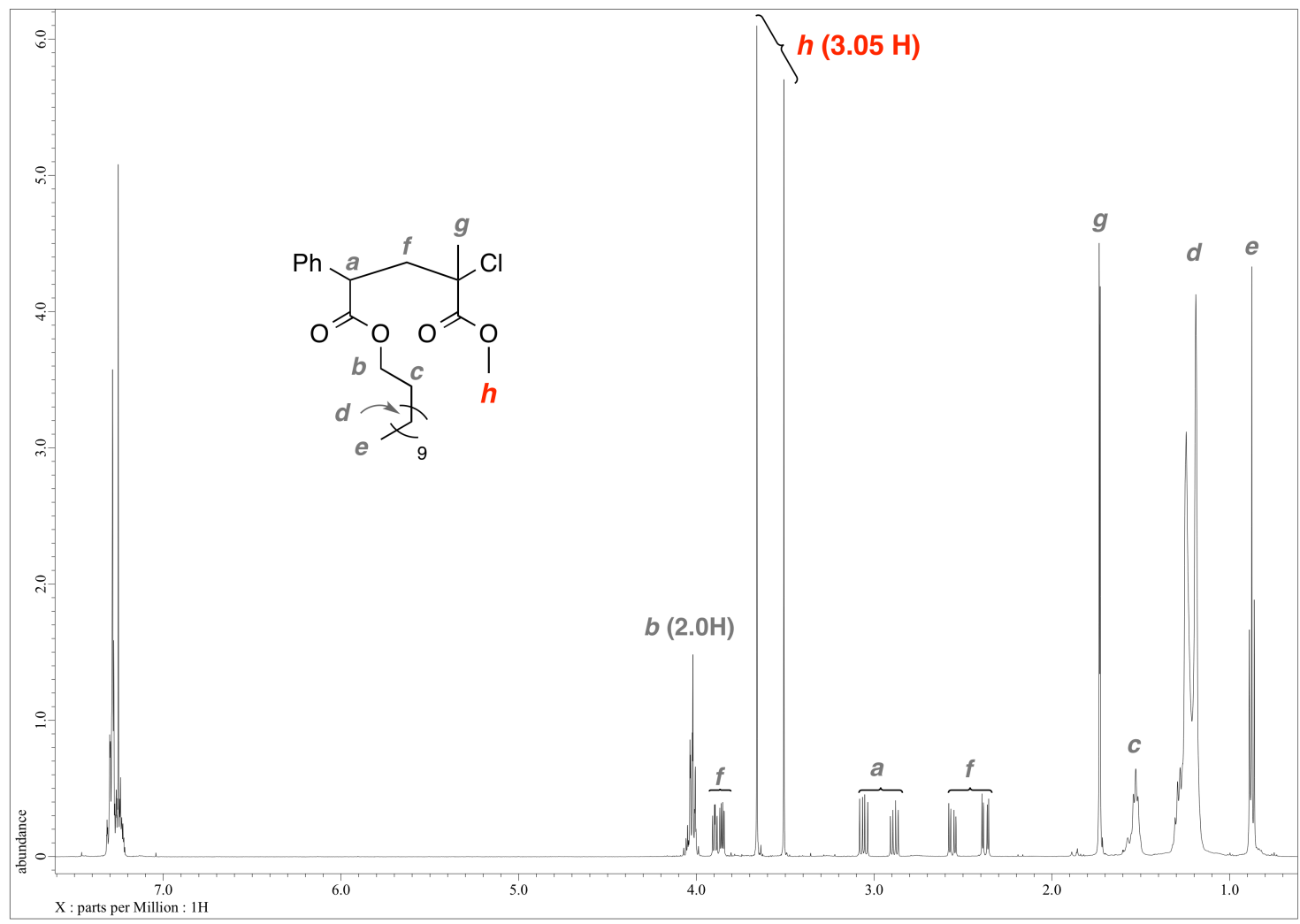

Figure S8. ${ }^{1} \mathrm{H}$ NMR Spectrum of Product after Esterification with Methanol $\left(1^{\text {st }}\right.$ Cycle $)$

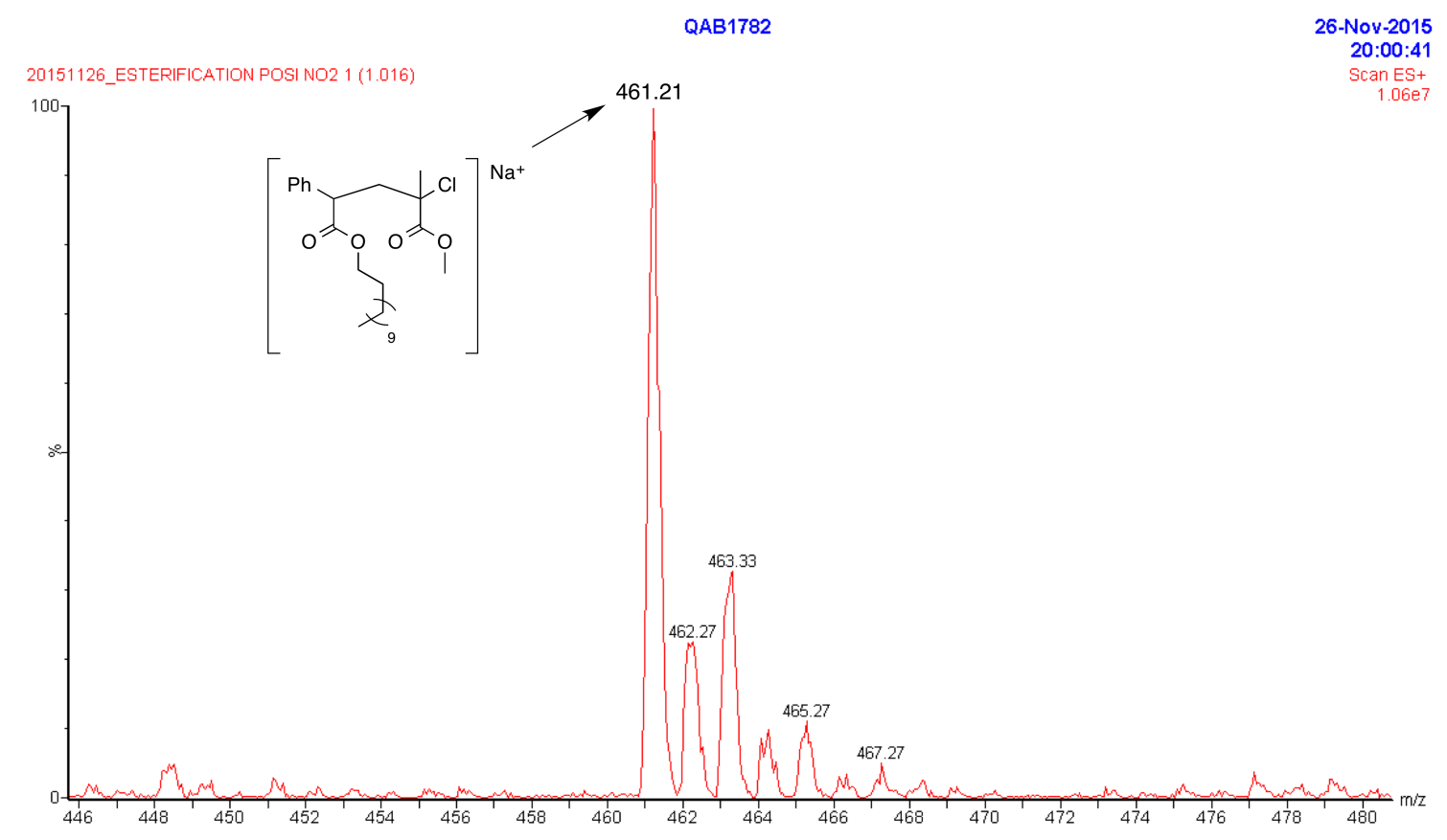

Figure S9. ESI-MS Spectrum of Product after Esterification with Methanol $\left(1^{\text {st }} \mathrm{Cycle}\right)$ 


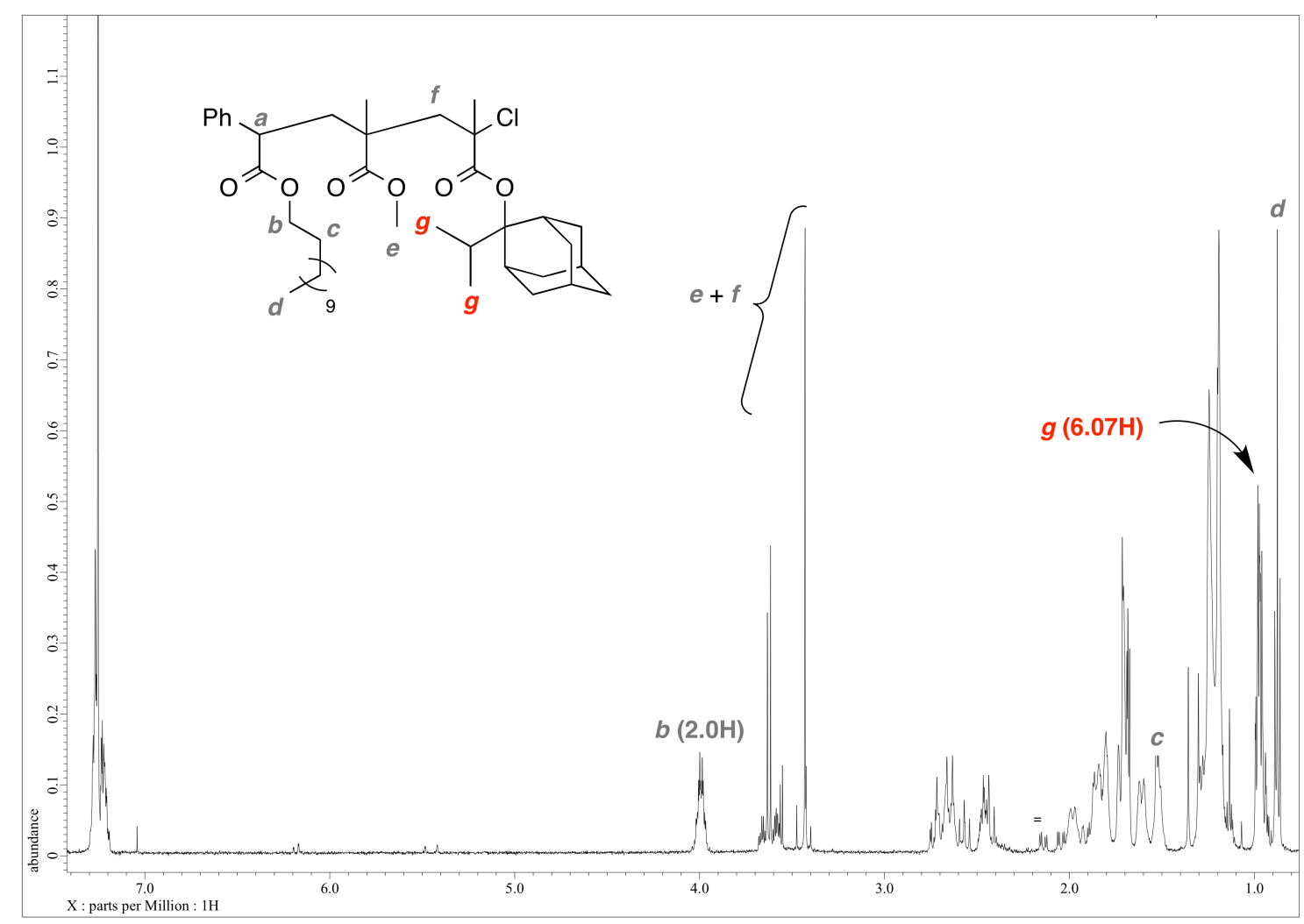

Figure S10. ${ }^{1} \mathrm{H}$ NMR Spectrum of Single-Adduct $\left(2^{\text {nd }}\right.$ Cycle $)$

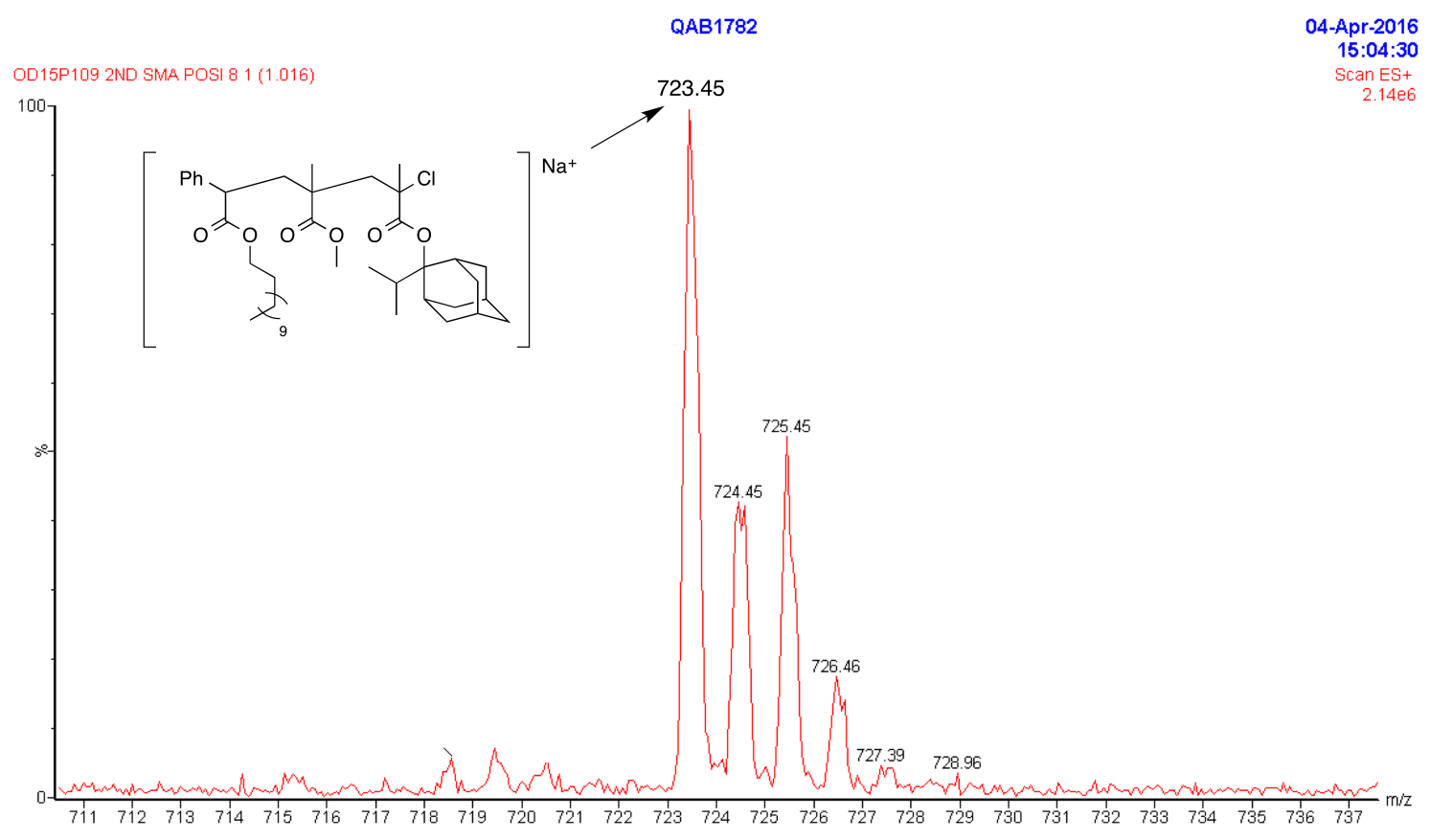

Figure S11. ESI-MS Spectrum of Single-Adduct $\left(2^{\text {nd }}\right.$ Cycle $)$ 


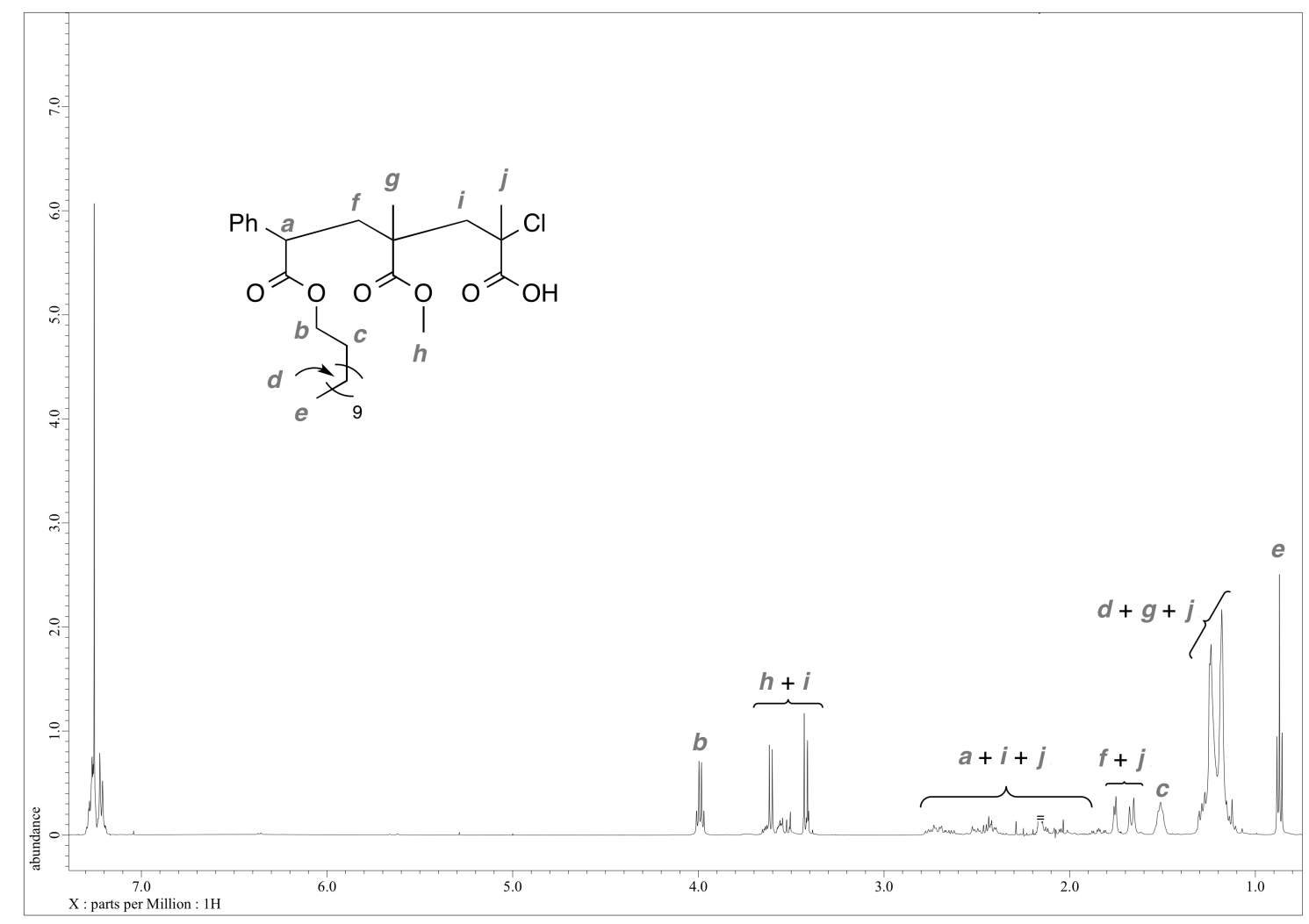

Figure S12. ${ }^{1}$ H NMR Spectrum of Product after Selective Cleavage $\left(2^{\text {nd }}\right.$ Cycle $)$

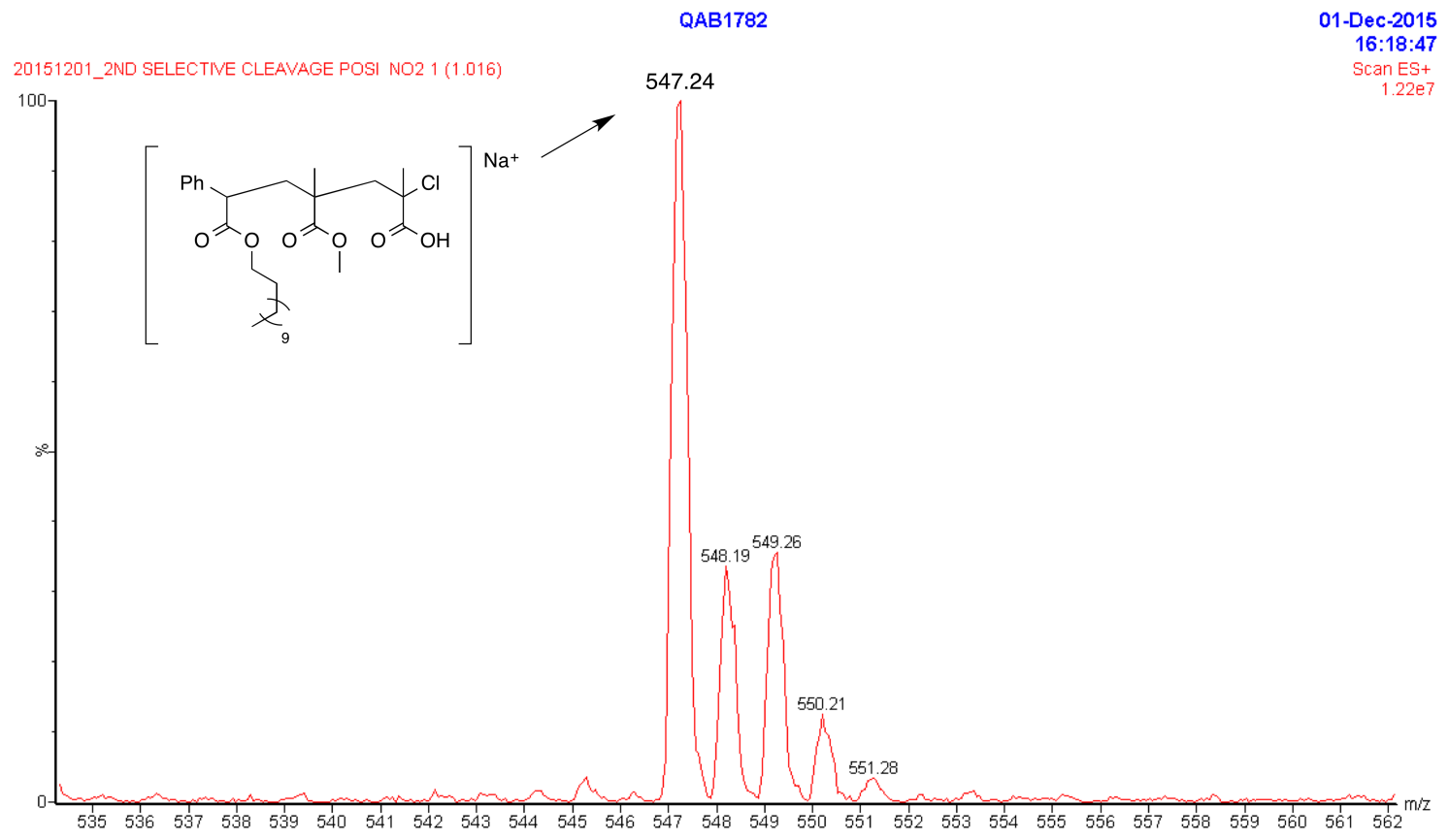

Figure S13. ESI-MS Spectrum of Product after Selective Cleavage $\left(2^{\text {nd }}\right.$ Cycle $)$ 


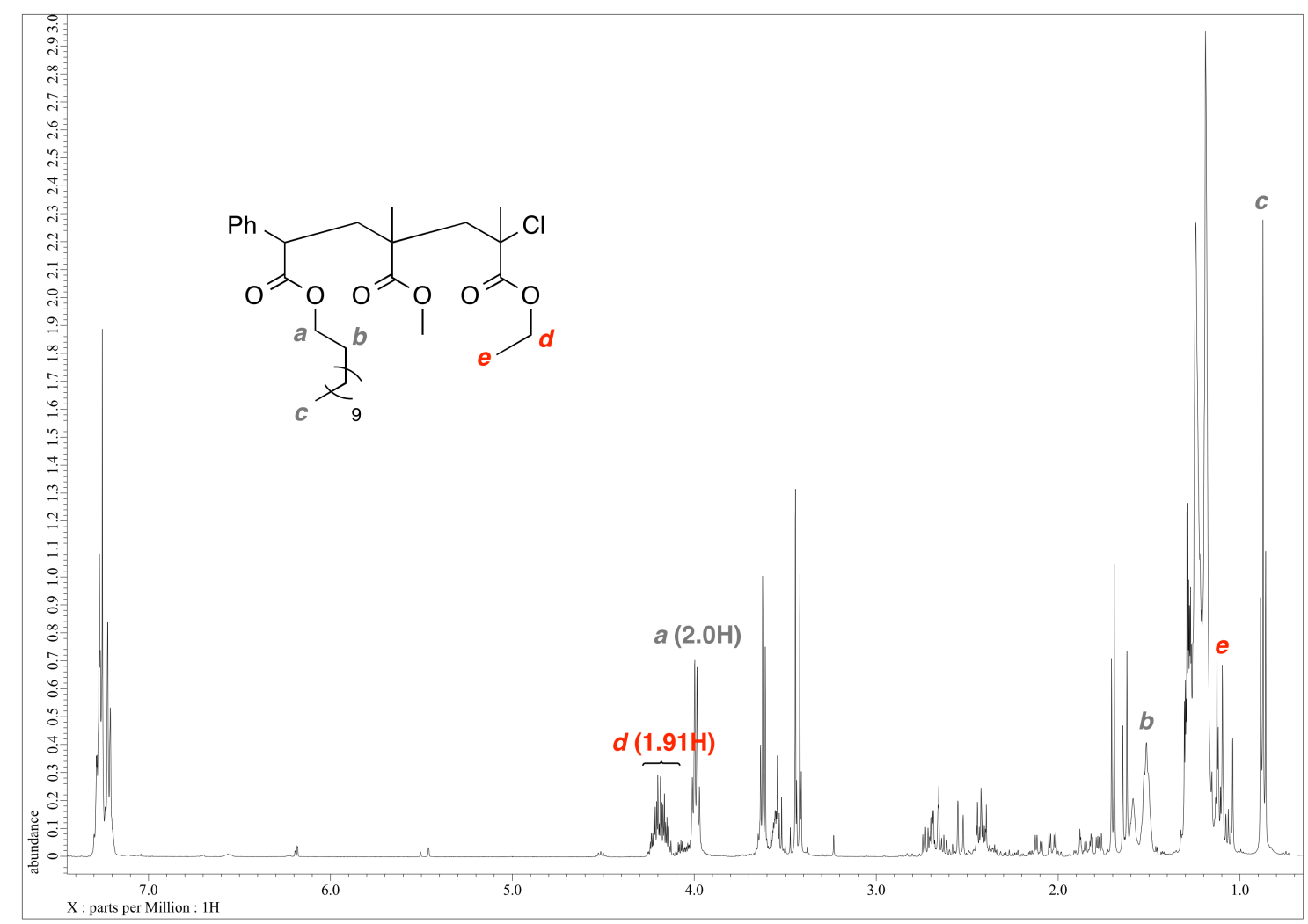

Figure S14. ${ }^{1} \mathrm{H}$ NMR Spectrum of Product after Esterification with Ethanol ( $2{ }^{\text {nd }}$ Cycle $)$

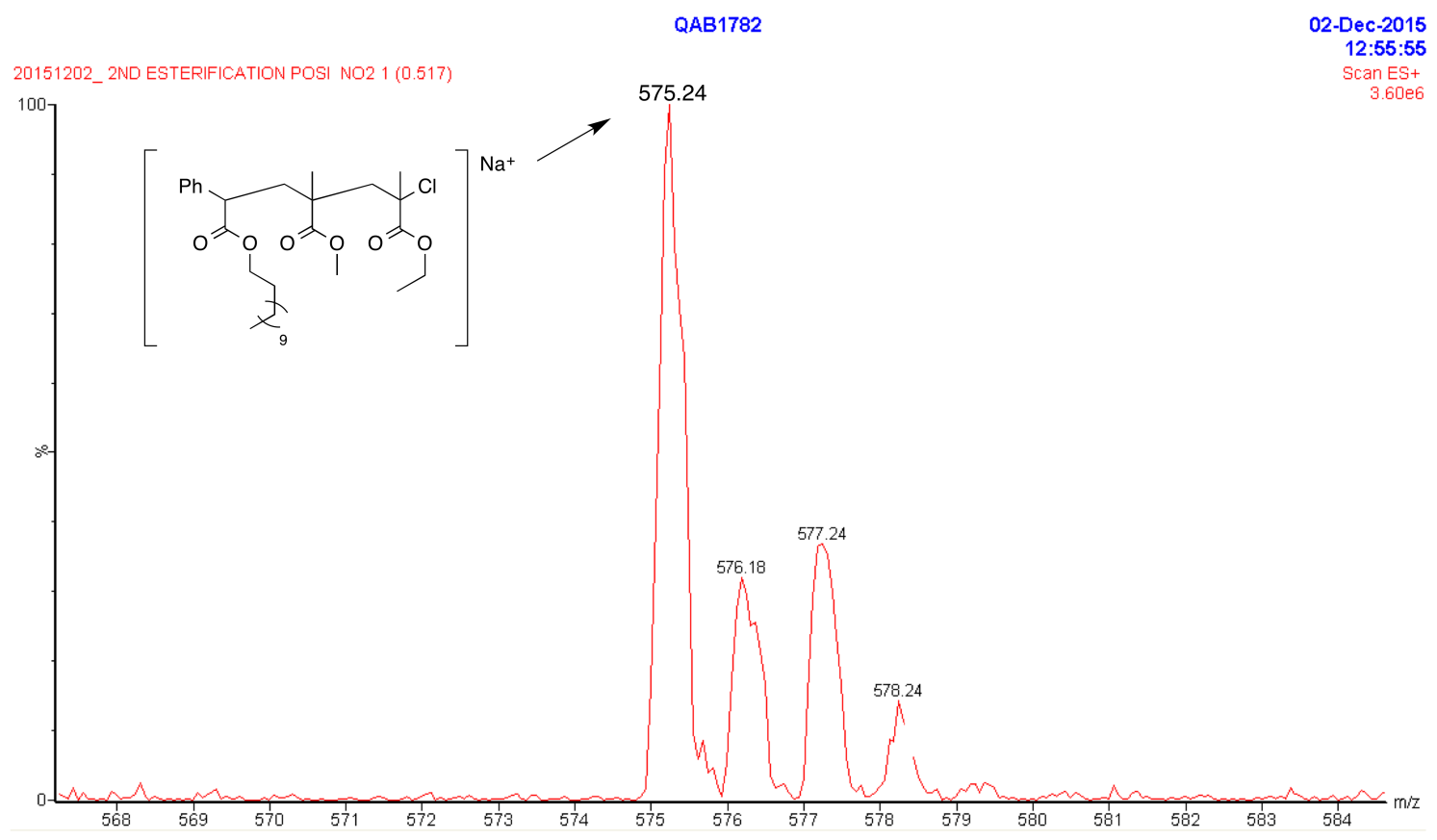

Figure S15. ESI-MS Spectrum of Product after Esterification with Ethanol $\left(2^{\text {nd }} \mathrm{Cycle}\right)$ 


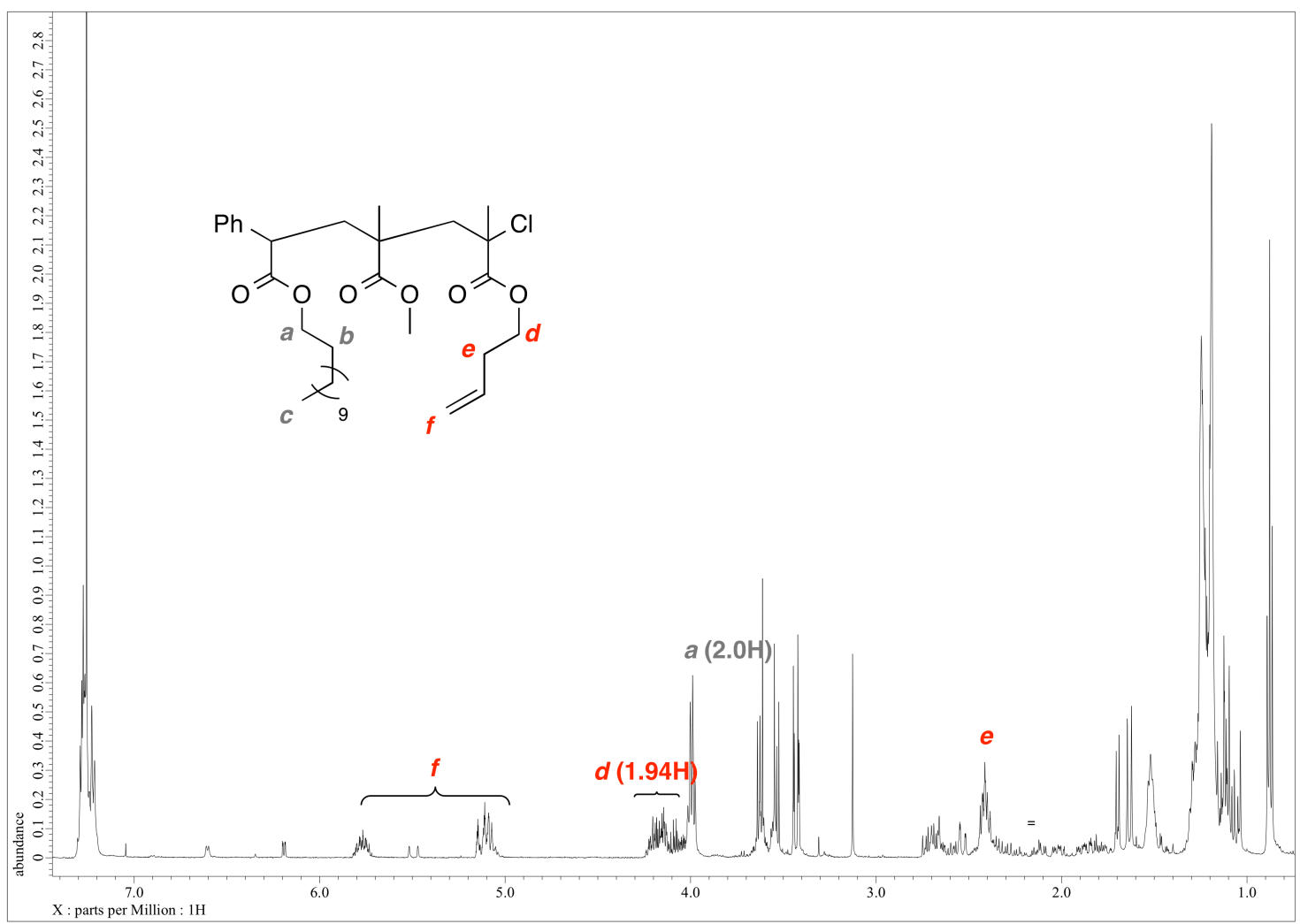

Figure S16. ${ }^{1}$ H NMR Spectrum of Product after Esterification with 3 -buten-1-ol ( $2^{\text {nd }}$ Cycle)

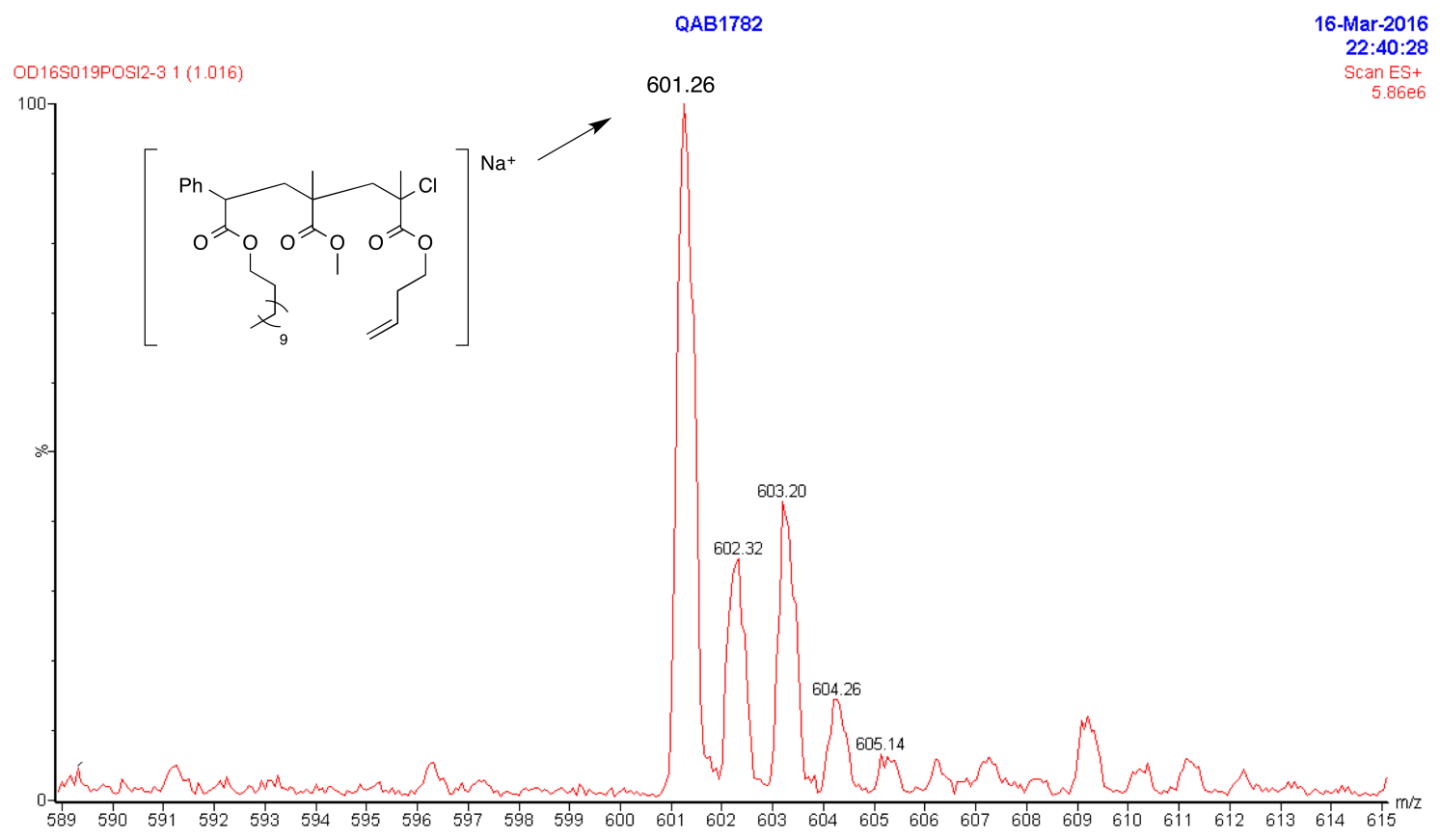

Figure S17. ESI-MS Spectrum of Product after Esterification with 3-buten-1-ol (2 ${ }^{\text {nd }}$ Cycle) 


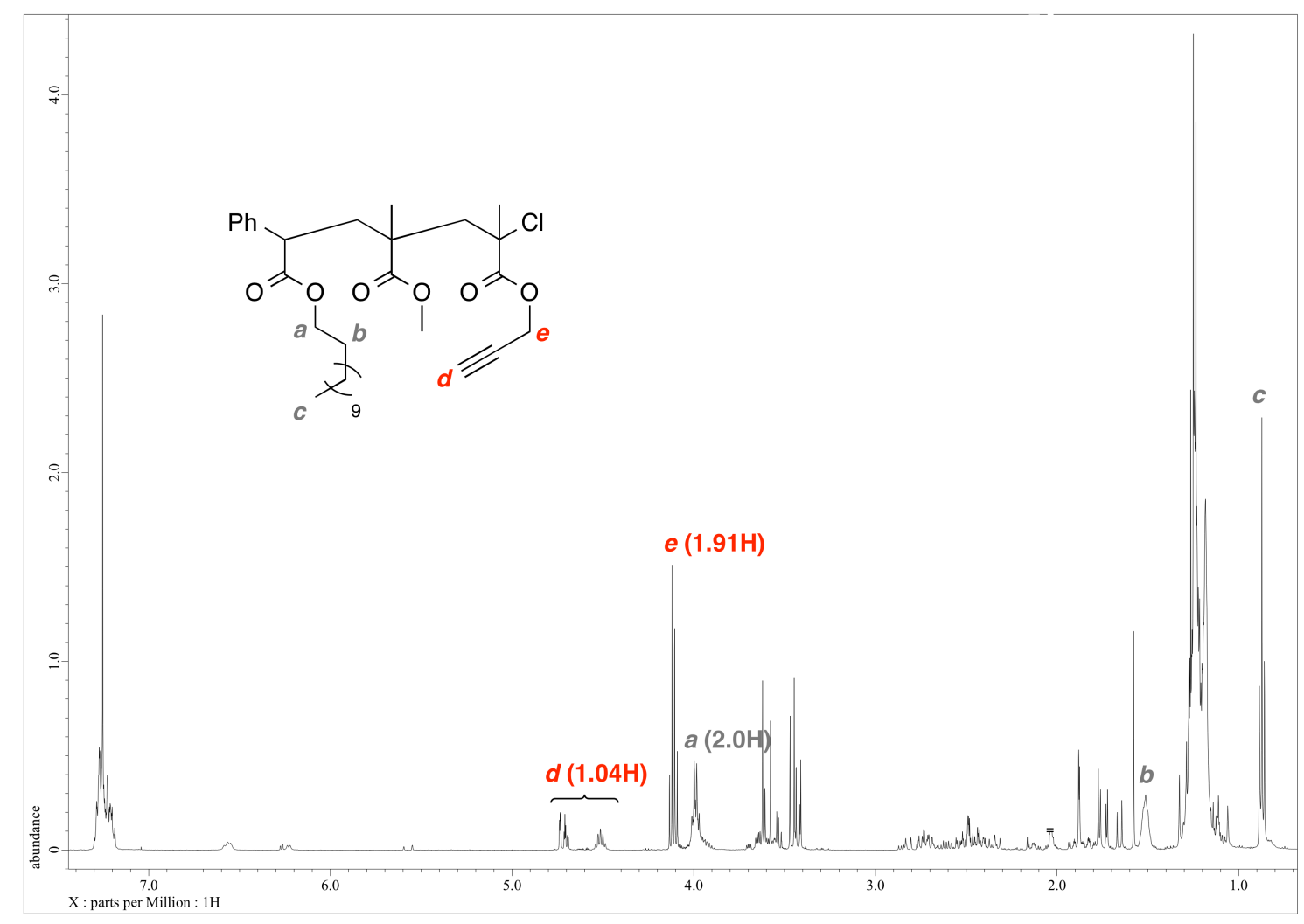

Figure S18. ${ }^{1}$ H NMR Spectrum of Product after Esterification with Propargyl alcohol ( ${ }^{\text {nd }}$ Cycle)

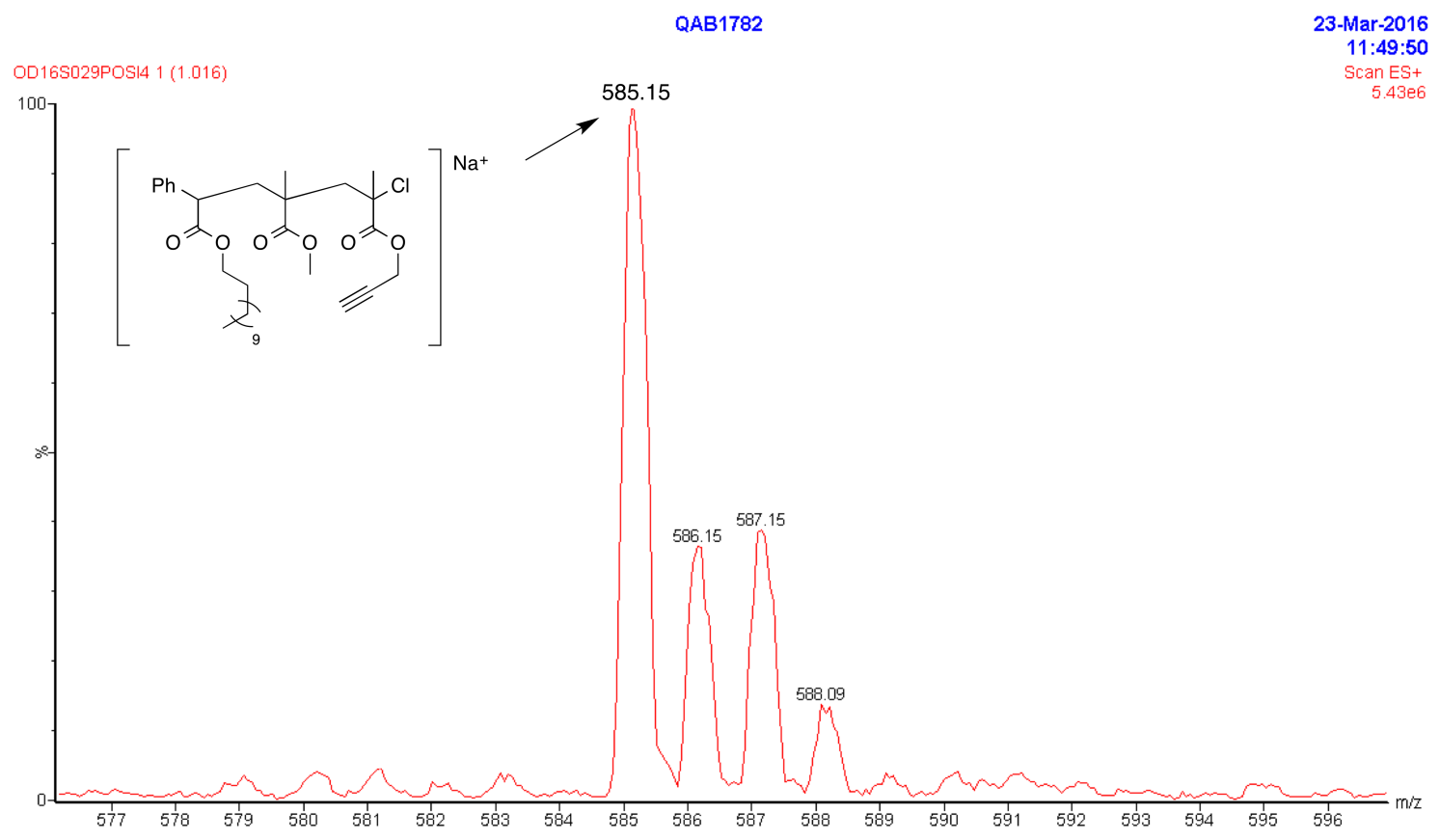

Figure S19. ESI-MS Spectrum of Product after Esterification with Propargyl alcohol $\left(2^{\text {nd }}\right.$ Cycle) 


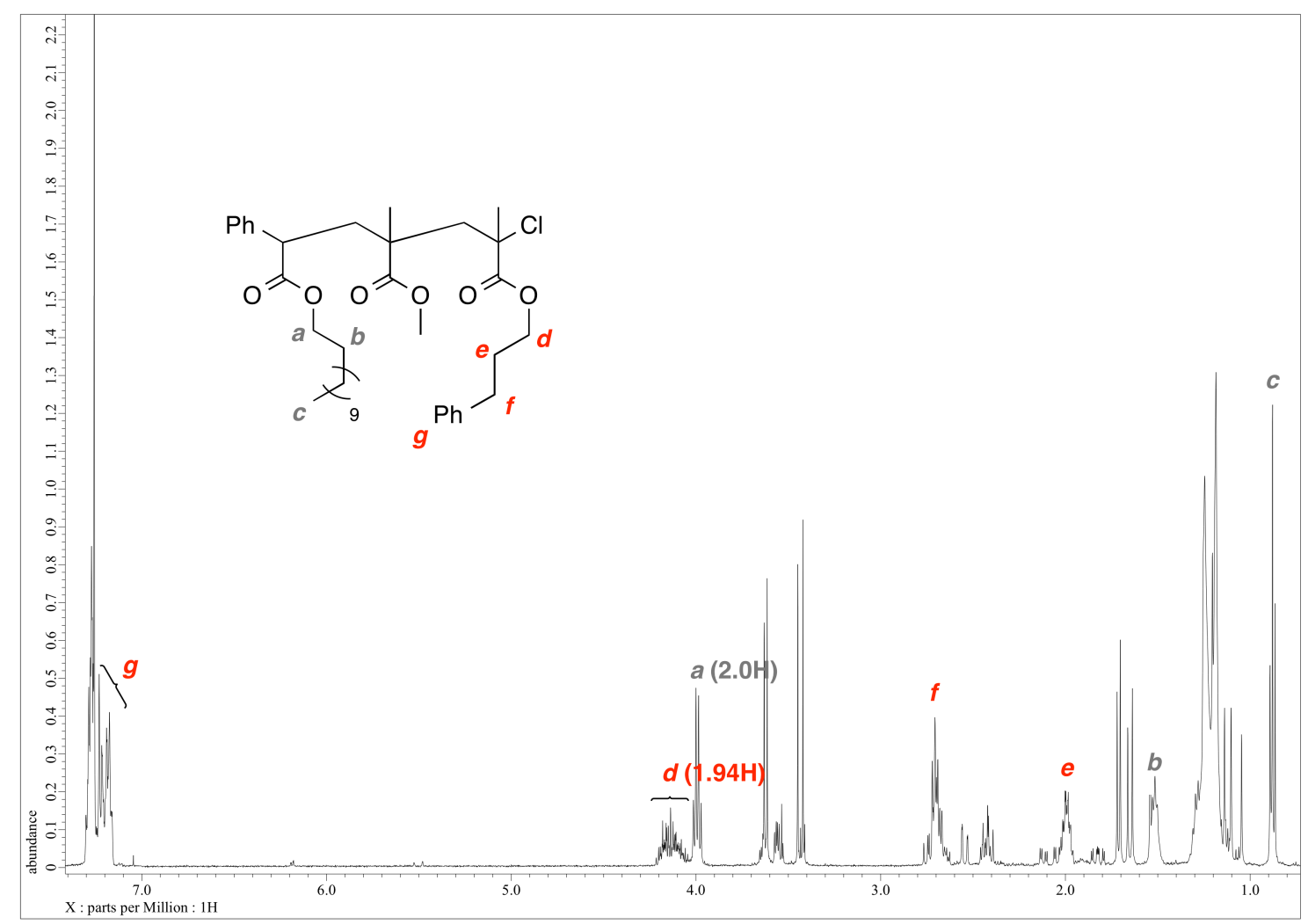

Figure S20. ${ }^{1}$ H NMR Spectrum of Product after Esterification with 3-phenyl-1-propanol ( ${ }^{\text {nd }}$ Cycle)

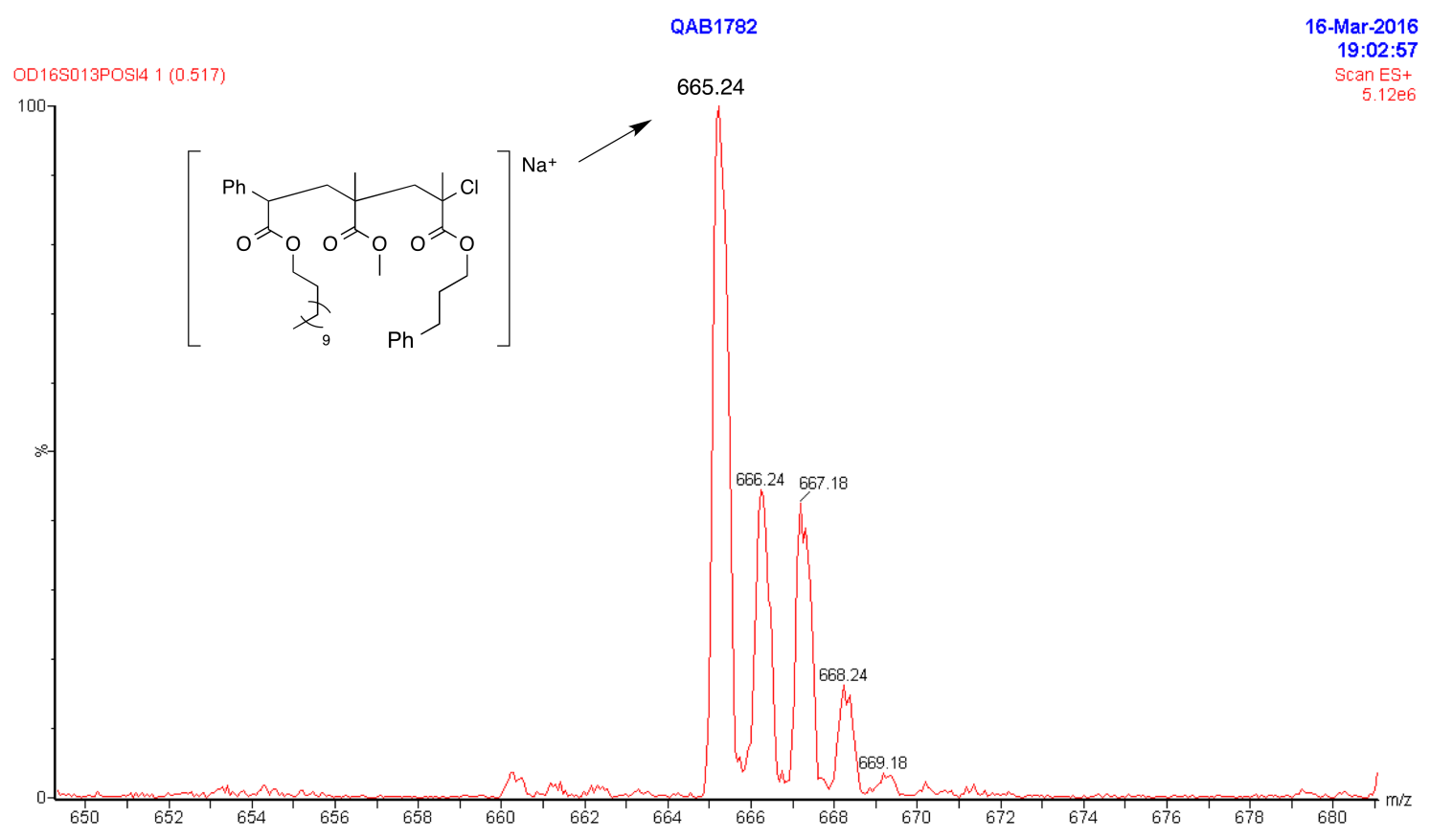

Figure S21. ESI-MS Spectrum of Product after Esterification with 3-phenyl-1-propanol ( ${ }^{\text {nd }}$ Cycle) 


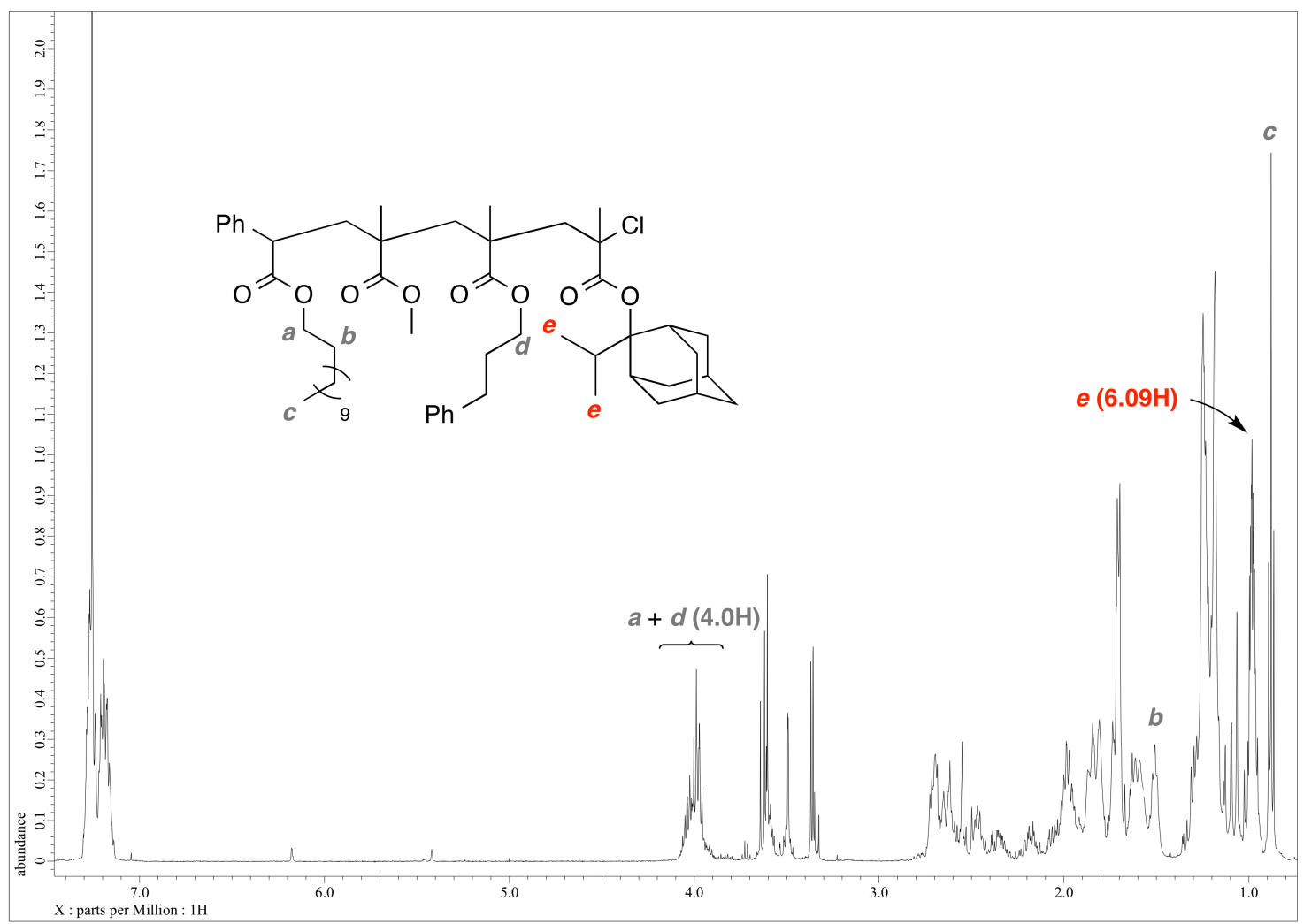

Figure S22. ${ }^{1} \mathrm{H}$ NMR Spectrum of Single-Adduct $\left(3^{\text {rd }}\right.$ Cycle $)$

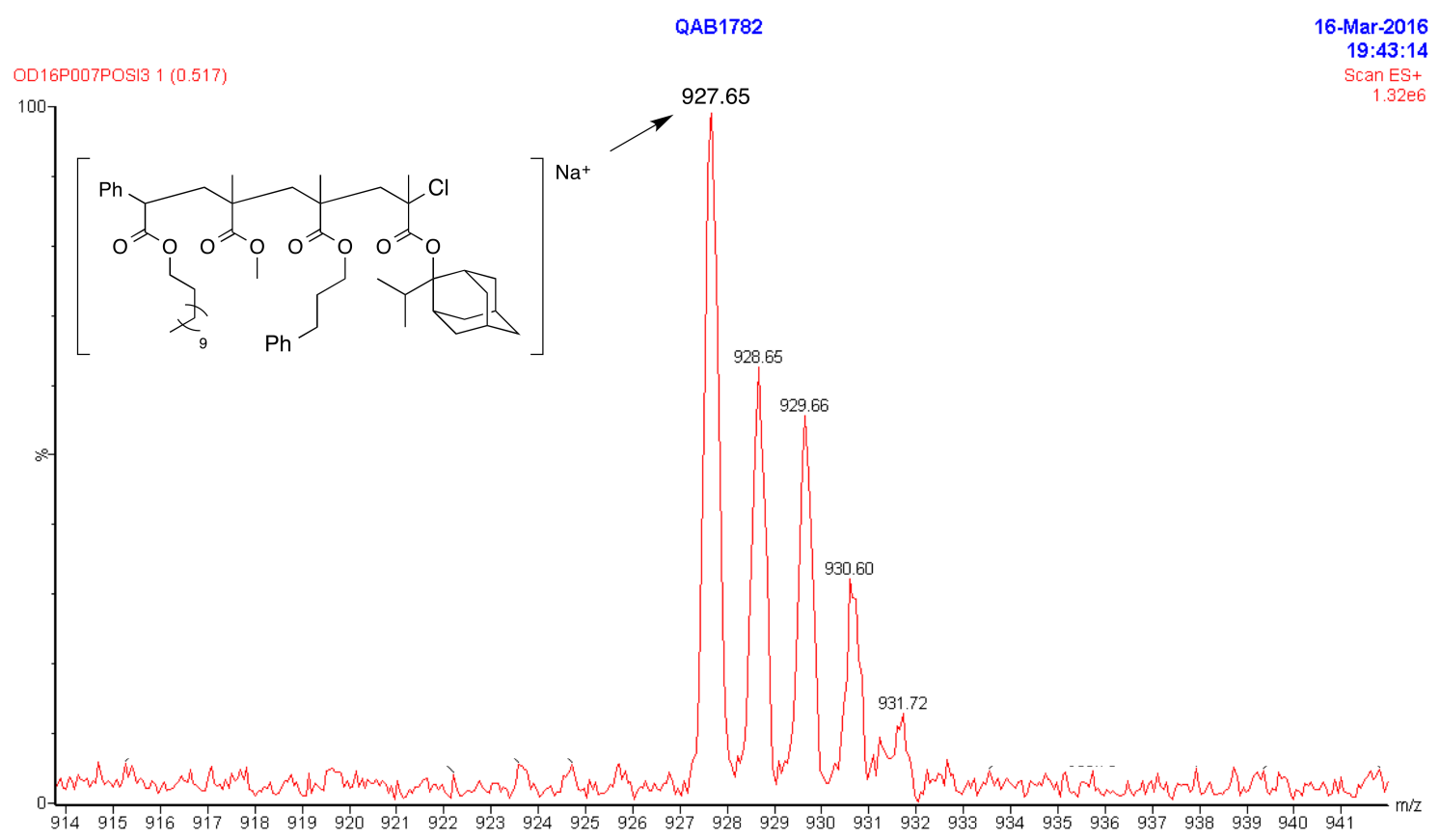

Figure S23. ESI-MS Spectrum of Single-Adduct $\left(3^{\text {rd }}\right.$ Cycle $)$ 


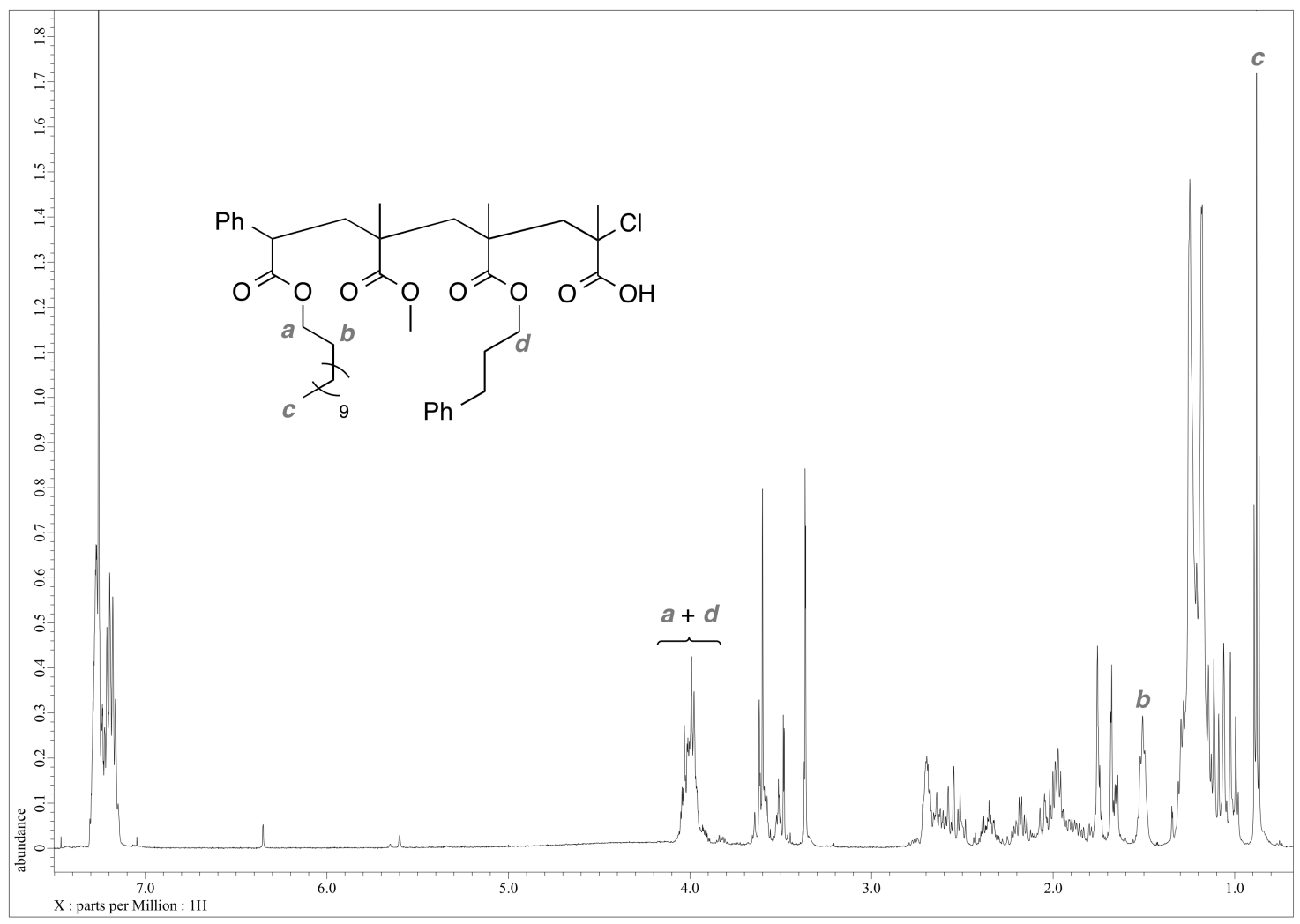

Figure S24. ${ }^{1}$ H NMR Spectrum of Product after Selective Cleavage $\left({ }^{\text {rd }}\right.$ Cycle $)$

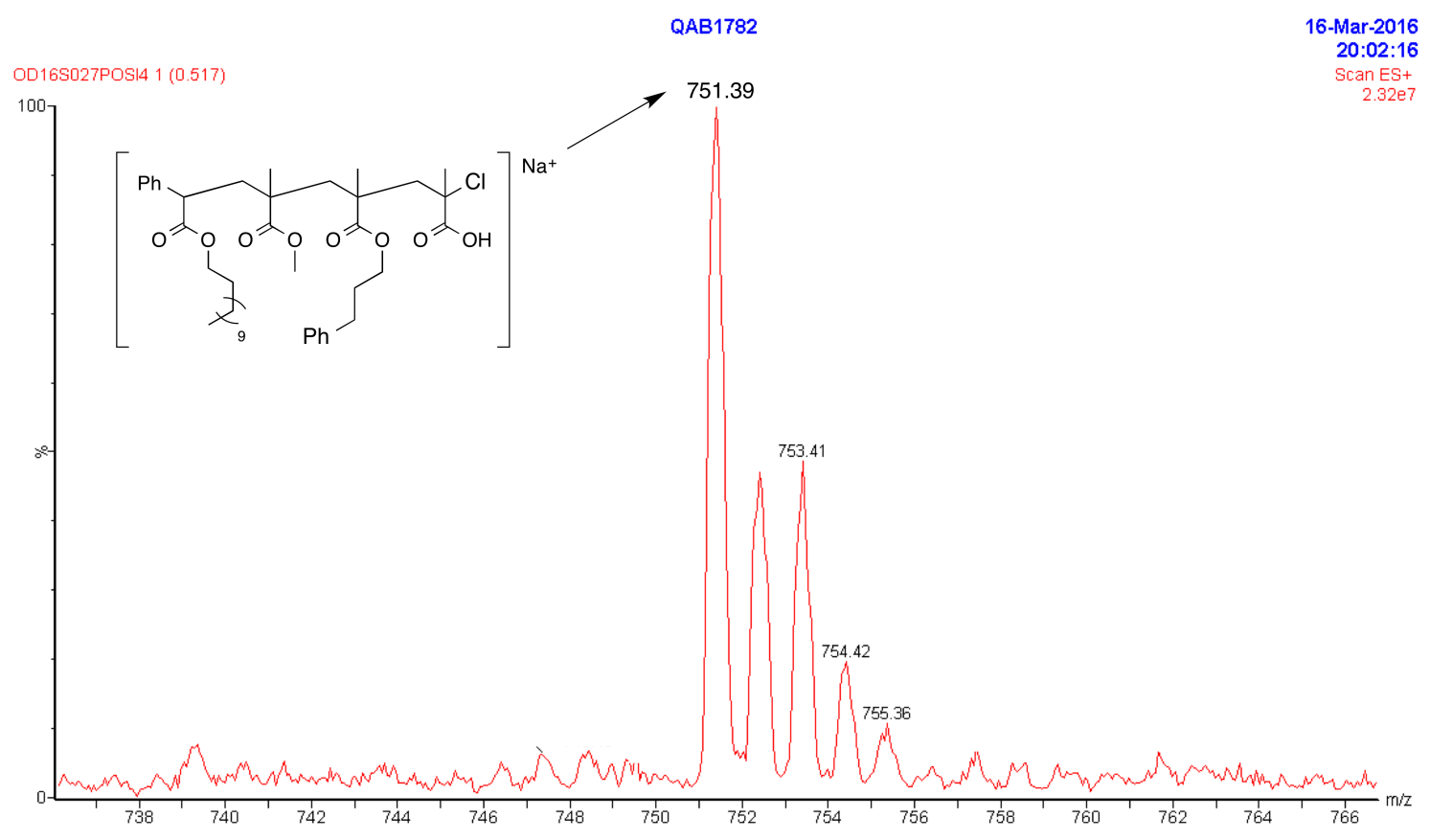

Figure S25. ESI-MS Spectrum of Product after Selective Cleavage $\left(3^{\text {rd }}\right.$ Cycle) 


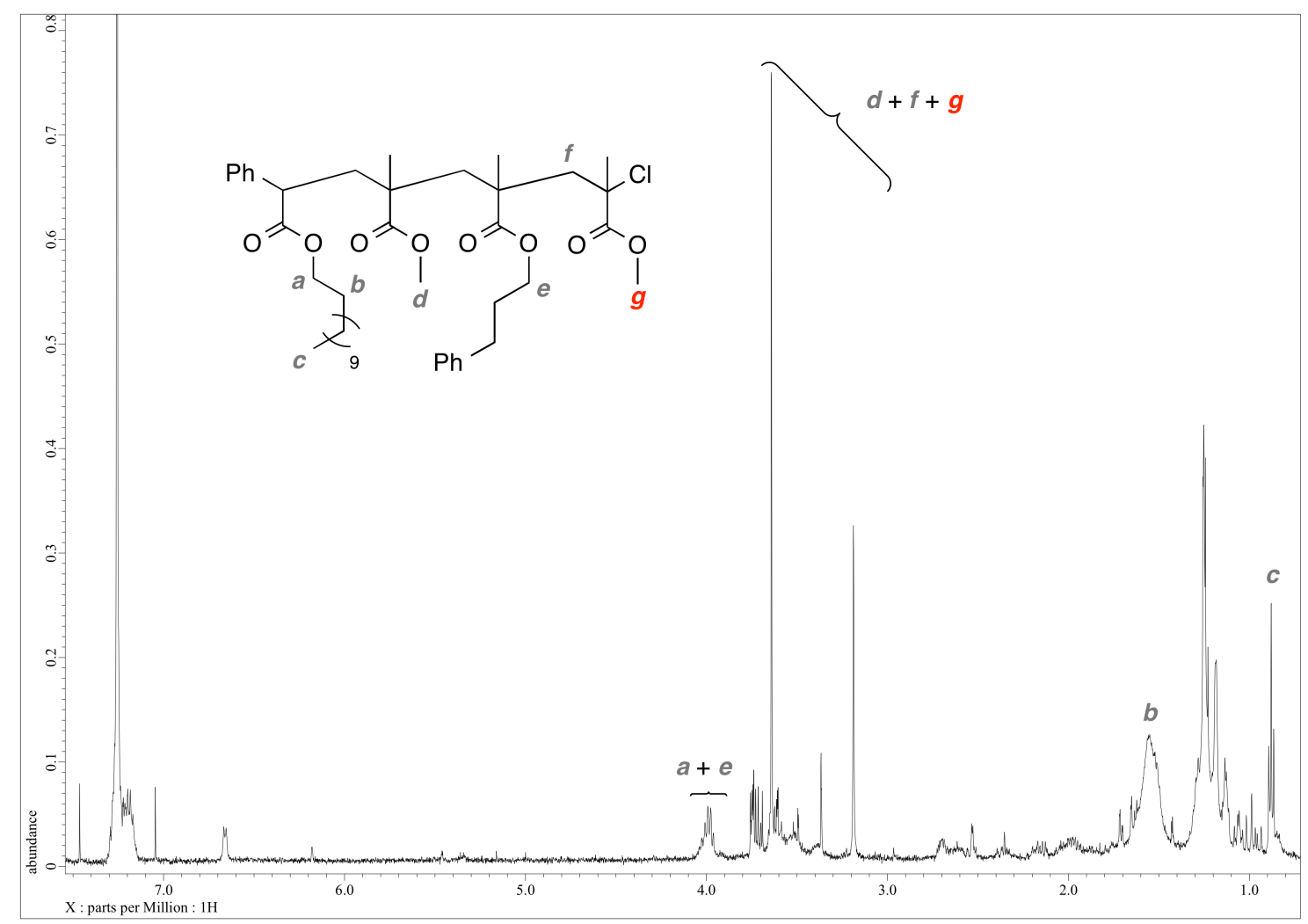

Figure S26. ${ }^{1}$ H NMR Spectrum of Product after Esterification with Methanol ( ${ }^{\text {rd }}$ Cycle)

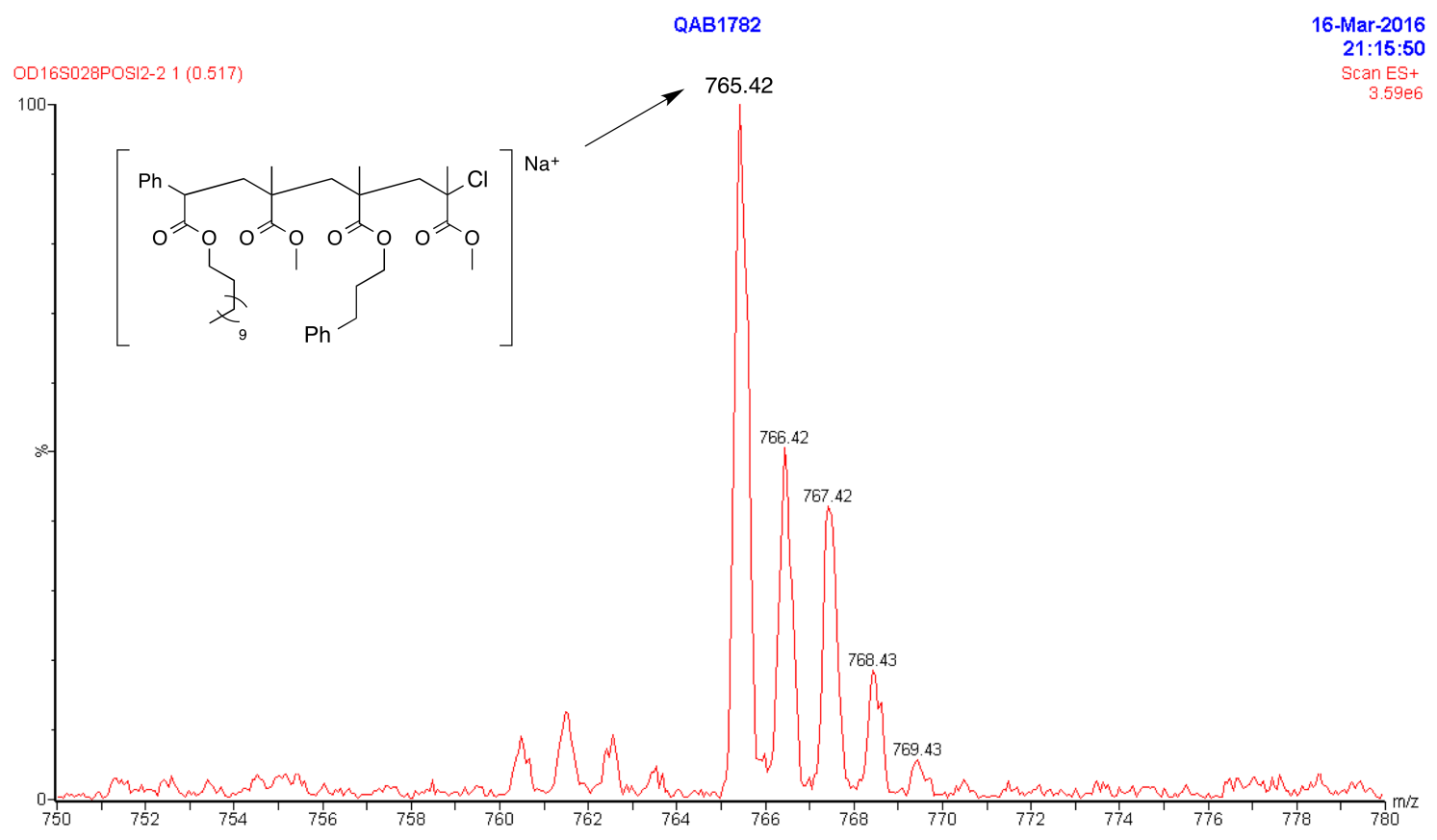

Figure S25. ESI-MS Spectrum of Product after Esterification with Methanol $\left(3^{\text {rd }}\right.$ Cycle $)$ 